\title{
Über die komplexe Genese mittelpleistozäner archäologischer Fundstellen am Beispiel des Platzes Kärlich-Seeufer (Mittelrhein)
}

\author{
SABINE GAUDZINSKI*) \\ Lower Palaeolithic, Middle Pleistocene, Elephas antiquus, wooden remains, Kärlich-Interglacial, \\ site formation processes
}

\begin{abstract}
Kurzfassung: Die mittelpleistozäne Fundstelle KärlichSeeufer ist der jüngste archäologische Nachweis innerhalb der Kärlicher Tongrube, die seit Anfang des Jahrhunderts als der wichtigste Aufschluß für das Quartär der Mittelrheinregion gilt.

Die Fundstelle wurde im Jahre 1980 entdeckt und in den Folgejahren ausgegraben. Zusammen mit einem altpaläolithischen Steingeräteinventar konnten zahlreiche Faunenreste, vor allem aber Hölzer und Fruchtreste geborgen werden, die durch eine exzellente Erhaltung gekennzeichnet sind. Hölzer von Abies und Quercus sind in der Hauptsache vertreten und haben sich in Form von Ästen und Baumstämmen erhalten. Die Faunengemeinschaft umfaßt Panthera leo ssp., Elephas antiquus, Equus sp., Sus scrofa, Cervus elaphus, Rangifer sp. sowie Bos vel Bison. Reste von Elephas antiquus dominieren. Überliefert sind vorwiegend Molaren, die sich, im Vergleich zu Zähnen anderer mittel- und jungpleistozäner Elephas antiquus-Populationen, durch besondere Robustheit auszeichnen.

Durch pollenanalytische Untersuchungen konnte die Bildung des fundführenden Sediments an der Fundstelle auf die zweite Hälfte einer Warmzeit, das Kärlich-Interglazial, eingegrenzt werden. Sie erlauben darüber hinaus eine detaillierte Rekonstruktion paläoökologischer Bedingungen während des Mittelpleistozäns.

Analysen zur Genese der Fundstelle, unter Berücksichtigung der fundführenden Sedimente, des lithischen Materials, der Fauna sowie der zahlreichen paläobotanischen Makroreste zeigen, daß der Platz als Sedimentfalle fungierte, in die Reste menschlicher Aktivitäten zusammen mit Holzund Faunenresten umgelagert wurden. Wie auch an anderen altpaläolithischen Fundstellen Europas, so können auch am Kärlicher Seeufer Aussagen über hominides Verhalten nur über die Artefakte getroffen werden. Der Zusammenhang zwischen hominiden Aktivitäten und den übrigen Fundgattungen bleibt ungewiß.
\end{abstract}

\section{[The complex formation of Middle Pleistocene archaeological sites using the Kärlich-Seeufer site as an example]}

Abstract: The Middle Pleistocene site Kärlich-Seeufer is the youngest archaeological site in the Kärlich clay pit which, since the beginning of this century, has been the

\footnotetext{
*) Anschrift der Verfasserin: Dr. S. Gaudzinski, Forschungsbereich Altsteinzeit des Römisch-Germanischen Zentralmuseums Mainz, Schloss Monrepos, 56567 Neuwied
}

most important exposure for Quaternary stratigraphy in the Central Rhineland.

The site was discovered in 1980 and excavated during the following years. Together with an Acheulean lithic assemblage and faunal remains, numerous macroscopic plant remains were recovered in an outstanding state of preservation. Wood of Abies and Quercus dominates the botanical assemblage in the form of trunks and branches. The faunal assemblage comprises: Panthera leo ssp., Elephas antiquus, Equus sp., Sus scrofa, Cervus elaphus, Rangifer sp. as well as Bos vel Bison. Elephas antiquus dominates the faunal assemblage and the molars of this species show a certain robustness in comparison to teeth of other Middle- and Upper Pleistocene Elephas antiquus populations.

The results of the palynological analysis show that the sediments containing the archaeological assemblage were deposited during the second half of an interglacial phase, the Kärlich Interglacial. Moreover, these results allow detailed reconstruction of palaeoecological conditions during the Middle Pleistocene.

Analysis of site formation processes, taking into account the sedimentology of the archaeological layers, the lithic and faunal assemblages and the numerous macroscopic palaeobotanical remains, shows that the Seeufer site functioned as a sediment trap in which evidence for hominid activity has been re-bedded together with wood and faunal remains. At Kärlich-Seeufer, as at other European Lower Palaeolithic sites, claims for hominid activity are very difficult to assess and can only be demonstrated for the lithic assemblage. The contribution of hominids to the presence of other categories of finds remains obscure.

\section{Einleitung}

Der Fundplatz Kärlich-Seeufer wurde im Jahre 1980 entdeckt. Systematische Ausgrabungen schlossen sich zwischen 1980 und 1982 und 1987-1992 durch G. Bosinski (Bosinski et al. 1980), K. Happe und J. KuleMEYER (KULEMEYER 1988), vor allem aber durch K. KRÖGER (KRÖGER et al. 1991) an. Während dieser Zeit konnten mehr als $417 \mathrm{~m}^{2}$ untersucht werden. Die Verfasserin unterzog das gesamte Fundmaterial zwischen 1992 und 1994 einer Analyse (GAUDZINSKI 1995a).

Der archäologische Befund des Platzes ist durch altpaläolithische Artefakte und die Dominanz von Elephas antiquus-Resten im Faunenmaterial gekenn- 
zeichnet. Besonders zu erwähnen ist die exzellente Erhaltung botanischer Reste in Form von Baumstämmen, Ästen, Fruchtresten und Pollen. Die paläobotanischen Reste erlauben eine detaillierte Rekonstruktion paläoökologischer Bedingungen während des Mittelpleistozäns.

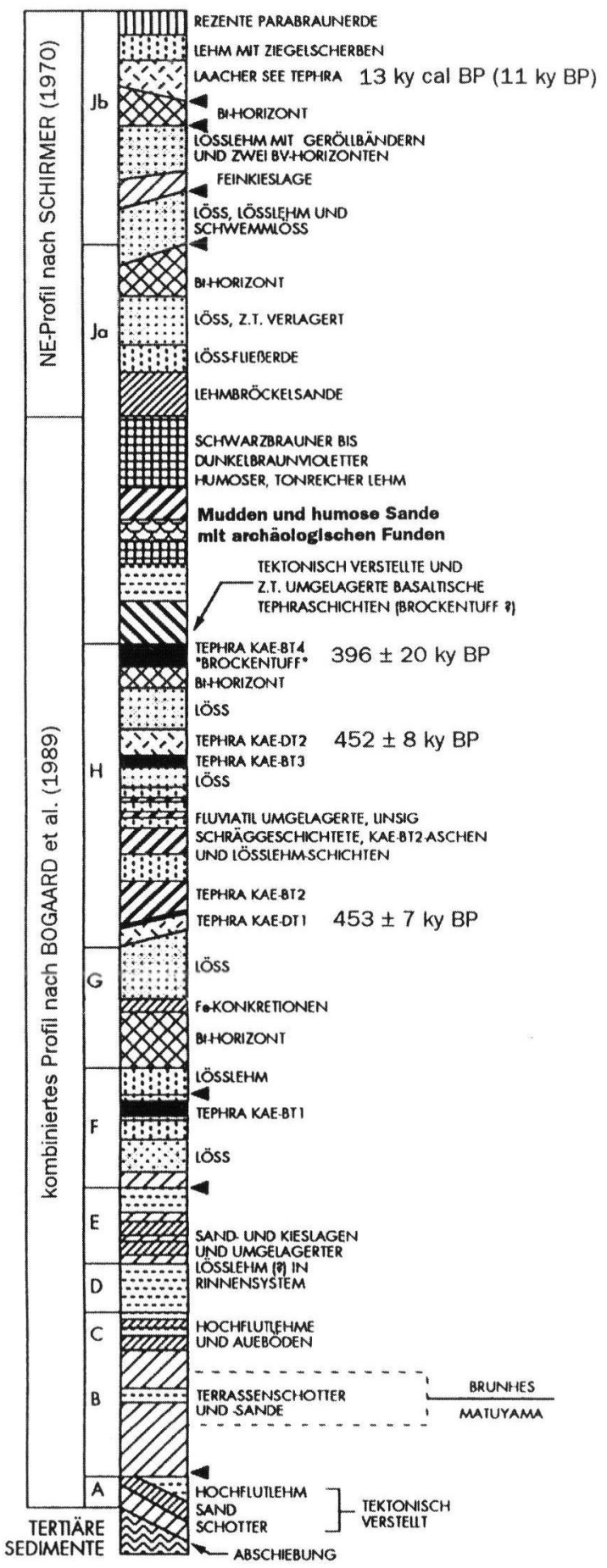

Von früheren Bearbeitern war der archäologische Befund am Kärlicher Seeufer zunächst als in situNachweis eines Elefantenjagdplatzes interpretiert worden (Bosinski 1983, Kulemeyer 1988, KrÖGER et al. 1991). Detaillierte Analysen zur Genese der fundführenden Sedimente, zum lithischen Material, der Fauna sowie den paläobotanischen Resten zeigen indes, daß der Platz eine Sedimentfalle darstellt, in die Reste menschlicher Aktivitäten zusammen mit Holz- und offenbar auch Faunenresten umgelagert wurden.

\section{Allgemeine Geologie}

Der Ort Kärlich liegt am Süd-Westrand des Neuwieder Beckens, ca. $10 \mathrm{~km}$ von Koblenz entfernt, am Fuße des Kärlicher Berges. Auf dessen Plateau ist die Tongrube der Fa. Mannheim gelegen. Durch industrielle Abraumarbeiten zur Gewinnung tertiären Tones ist hier eine mächtige mittelpleistozäne Abfolge aufgeschlossen.

Seit Beginn dieses Jahrhunderts ist die Tongrube Kärlich als der wichtigste Aufschluß für das Quartär der Mittelrheinregion bekannt. Die bis zu $30 \mathrm{~m}$ mächtigen Ablagerungen repräsentieren Sedimente vom Ende des Altpleistozäns bis zum oberen Mittelpleistozän.

Die Pleistozänabfolge in Kärlich (Abb. 1) beginnt im wesentlichen mit Hauptterrassenschottern (RAZI RAD 1976, Boenigk 1978). Die Schotter im unteren Teil wurden vom Rhein abgelagert. Sie sind revers magnetisch polarisiert. Die oberen Schotter repräsentieren dagegen Moselablagerungen, die, wie auch alle Sedimente im Hangenden der Abfolge, normal magnetisch polarisiert sind (Boenigk et al. 1974). Die Brunhes-Matuyama-Grenze soll am Übergang von Rhein- zu Moselschottern liegen. Die Deckschichten bestehen aus Löß und Lößderivaten mit eingeschalteten interglazialen Böden und Tephralagen (BRUNNACKER et al. 1969, SCHIRMER 1990). Vulkanische Aktivitäten sind im Rheinland erstmals durch den $\mathrm{Ab}$ schnitt $G$ der Kärlicher Abfolge mit dem Nachweis vulkanischer Minerale und basaltischer Tephralagen belegt. Aus diesem Abschnitt stammt darüber hinaus eine interglaziale Kleinsäugerfauna, cromerzeitlichen Alters, charakterisiert durch das erste Auftreten von Arvicola (V. KOlFsCHOTEN \& TuRner 1995).

In die Sedimente des hangenden Abschnitt H (Abb.

Abb. 1: Schematisiertes Gesamtprofil der Tongrube Kärlich, modifiziert nach Kröger et al. (1991). Zusammenstellung der physikalischen Alter: KAE-DT1: LipPolt et al. (1986), KAE-DT2, KAE-BT4: v. D. BOgAARD et al. (1989), Laacher See Tephra (cal): STREeT et al. (1994).

Fig. 1: Schematic main profile, Kärlich clay pit, modified after KRÖGER et al. (1991). Compilation of physical ages: KAE-DT1: Lippolt et al. (1986), KAE-DT2, KAE-BT4: v. D. BOgAARD et al. (1989), Laacher See Tephra (cal): STREET et al. (1994). 
1) sind zwei Tephralagen eingeschaltet, für die ein Alter um $450 \mathrm{ky} \mathrm{BP}$ auf der Basis von ${ }^{40} \mathrm{AR} /{ }^{39} \mathrm{AR}$ Stufenheizung- und Lasereinzelkristalldatierungen (LIPpolt et al. 1986, V. D. BogAAARD \& SCHMINCKe 1990) ermittelt wurde. Der Abschnitt $\mathrm{H}$ wird durch eine Bodenbildung abgeschlossen. Aus diesem Horizont stammt eine warmzeitliche Molluskenfauna, die ein Interglazial repräsentiert, das als das Kärlich-Interglazial beschrieben worden ist (BRUNNACKER et al. 1969, 1971).

Darüber folgt der sogenannte Kärlicher Brockentuff, eine bis zu $6 \mathrm{~m}$ mächtige Tephra, die durch mehrere monogenetische, phreatomagmatische Eruptionen entstand. Neben magmatischen Komponenten setzt sich der Brockentuff aus verbrannten Tonblöcken, Geröllen aus den beim Vulkanausbruch durchschlagenen Flußterrassenschottern, Lößfetzen und Stücken devonischen Schiefers aus dem Untergrund des Rheinischen Schiefergebirges zusammen. Für die Entstehung dieser Tephra wird auf der Basis von ${ }^{40} \mathrm{AR} /{ }^{39} \mathrm{AR}$ Lasereinzelkristalldatierungen ein Alter von $396 \pm 20 \mathrm{ky}$ BP postuliert. Mit dem Brockentuff endet im wesentlichen die Abfolge des Kärlicher Hauptprofils.

Nur in einer Depression in der Süd-Ost-Ecke der Tongrube setzt sich der Nachweis fort. Über dem Brockentuff akkumulierten hier warmzeitliche Ablagerungen, über denen wiederum die Sedimente abgelagert wurden, die die archäologischen Funde enthalten.

\subsection{Geologie der Fundstelle}

Der Fundplatz Kärlich-Seeufer liegt innerhalb einer Depression. Obwohl deren Entstehung kontrovers diskutiert wird (BOSINSKI et al. 1980, v. D. BOGAARD et al. 1989, SCHIRMER 1990), lassen phreatomagmatische Eruptionszentren eines oder mehrerer östlich des Fundplatzes gelegener Maare einen vulkano-tektonischen Ursprung plausibel erscheinen (GAUDZINSKI et al. 1995).

Als Folge der Instabilität der Hänge traten unmittelbar nach der Entstehung der Depression kleinere und größere Rutschungen auf, bei denen Moselschotter, umgelagerter Brockentuff und Sedimente die lithologisch mit denen der Abschnitte E, F und $\mathrm{H}$ der Kärlicher Gesamtabfolge vergleichbar sind, abgelagert wurden. Tone schwemmten aus dem Brockentuff aus; es bildete sich eine Tonschicht; ein Gewässer entstand.

Die Sedimente der hangenden Abfolge werden zunehmend feinkörniger und der Gehalt an organischem Material nimmt zu. Während einer stabilen Phase mit sehr geringer Sedimentation wurden Feindetritusmudden sedimentiert, die zum Randbereich der Depression hin in Grobdetritusmudden übergehen (Abb. 2, Schicht IV). Über diesen wurden die fundführenden Sedimente durch "debris flows" in einem Paket von bis zu 2,40 m Mächtigkeit abgelagert. Das Paket setzt sich aus mindestens 4 Ablagerungen zusammen (Abb. 2, Schicht IIIa-Schicht I), die zu unterschiedlichen Quantitäten aus umgelagertem Brockentuff, Sand, Lehm und Lapilli bestehen und die sich unterschiedlich über die Grabungsfläche ausdehnen (vgl. Abb. 4). Aus südlicher und westlicher Richtung fällt die Depression, in der diese Sedimente abgelagert wurden, stark ein und deren Neigungswinkel kann bis zu $50^{\circ}$ betragen. Wie auch bei den Mudden, so nimmt die Feinkörnigkeit der Ablagerungen zum Zentrum der Hohlform hin zu.

Durch Schlammströme wurden in der Folgezeit Tone, Schluffe und drei Horizonte organischer Ablagerungen in einem Paket von bis zu $2 \mathrm{~m}$ Mächtigkeit geschichtet sedimentiert (Abb. 1, Abb. 2, Schicht 0). Im hangenden Bereich der obersten organischen Ablagerung läßt sich ein deutlicher Sedimenationswechsel fassen. Ein bis zu $10 \mathrm{~m}$ mächtiges Paket geschichteter Ablagerungen, mit einem Farbwechsel von grau über schwarz zu braun, zeigt an, daß kein Gewässer mehr bestand. Die Sedimentation erfolgte nun durch Hangabspülungen. Die Korngröße der Ablagerungen wechselt von feinkörnig zu grobkörnig, schluffig und auch sandig. In diese Abfolge sind zwei hellgraue Pseudogleyböden eingeschaltet, die eine Sedimentationsunterbrechung anzeigen. Die
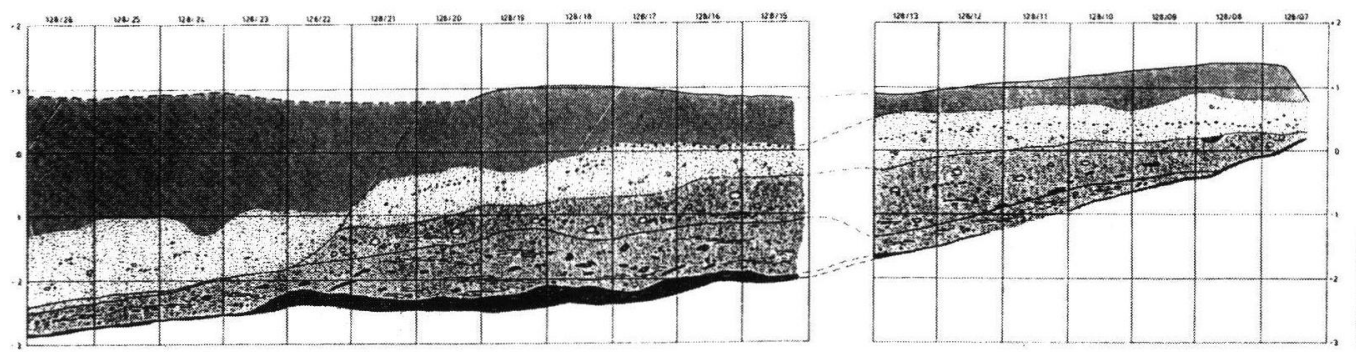

Abb. 2: Ostprofil der Grabung am Fundplatz Kärlich-Seeufer.

Fig. 2: East profile, excavation Kärlich-Seeufer. 


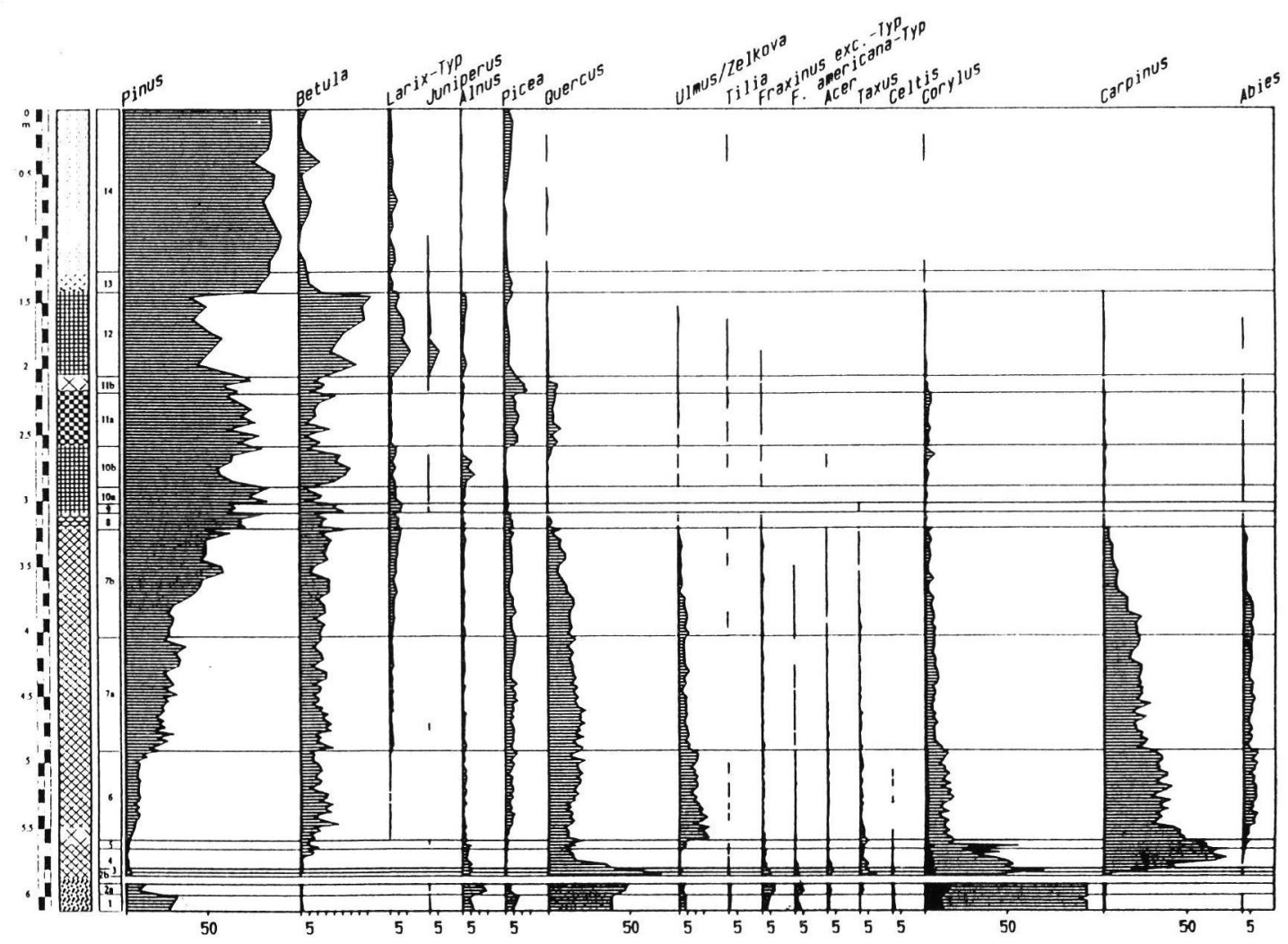

Abb. 3: Vereinfachtes Pollendiagramm des Profils Kärlich E. Berechnungsgrundlage auf der Basis der Baumpollen ohn Fig. 3: Simplified pollen diagram of the profile Kärlich E. Pollen sum calculated on the basis of the tree pollen excluded Corylus

Abfolge wird durch einen tonreichen braune'n Boden, Reste des Bt-Horizontes einer Parabraunerde, die eine Schichtlücke anzeigen, abgeschlossen. Die Sequenz am Kärlicher Seeufer endet mit unverwittertem gelbem, karbonatreichem Löß (GAUDZINSKI et al. 1995).

\section{Paläobotanik}

Die Ergebnisse palynologischer Untersuchungen ermöglichten detaillierte Umwelt- sowie Klimarekonstruktionen vor und zum Zeitpunkt der Bildung der fundführenden Sedimente (BITTMANN 1991, 1992). Die limnischen und telmatischen Ablagerungen oberhalb des umgelagerten Brockentuffs wurden palynologisch untersucht. Die von F. BiTTMAnN durchgeführten Arbeiten zeigten, daß die „debrisflows" während des zweiten Teils einer Warmzeit abgelagert wurden, die dem Kärlich-Interglazial zugerechnet wird (BITTMANN 1991).

Es konnten insgesamt 5 Pollenprofile studiert werden, von denen zwei in der Umgebung der Grabungsstelle liegen und den zweiten Teil des Interglazials charakterisieren. Drei weitere Profile stammen aus dem Bereich der Grabungsfläche und charakterisieren die Umwelt während der Ablagerung des archäologischen Materials.
Insgesamt umfaßt der palynologische Nachweis sechs Phasen mit 14 lokalen Pollenzonen, die das Interglazial sowie den Beginn der nachfolgenden Kaltzeit umfassen und im folgenden beschrieben werden (Bittmann 1991) Abb. 3).

Quercetum mixtum-Phase (lokale Pollenzonen 1-3) Die Eichenmischwaldphase muß als das klimatische Optimum der Warmzeit betrachtet werden. Im Pollendiagramm erreichen die thermophilen Arten wie Celtis, Cornus mas, Hedera und Syringa ihre höchsten Werte und nur in dieser Phase konnte der Wasserfarn, Azolla filiculoides, nachgewiesen werden. Die Vegetation zeigt an, daß sich die Gewässerbedingungen von mesotroph zu eutroph änderten.

Die Carpinus-Eichenmischwald-Phase

(lokale Pollenzonen 4-7).

Zu Beginn dieses Abschnittes wird die Eiche von der Hainbuche als dominierende Baumart abgelöst. Ab der Pollenzone 4 zeigt eine niedermoorartige Vegetation, daß meso-eutrophe Bedingungen im Gewässer herrschten. Gegen Ende der Zone 6 verschlechtert sich das Klima erkennbar. Von nun ab werden die thermophilen Waldgesellschaften der frühen Carpinus-Eichenmischwald-Zeit zusehends von borealen Nadelwäldern und Zwergstrauchgebüschen 


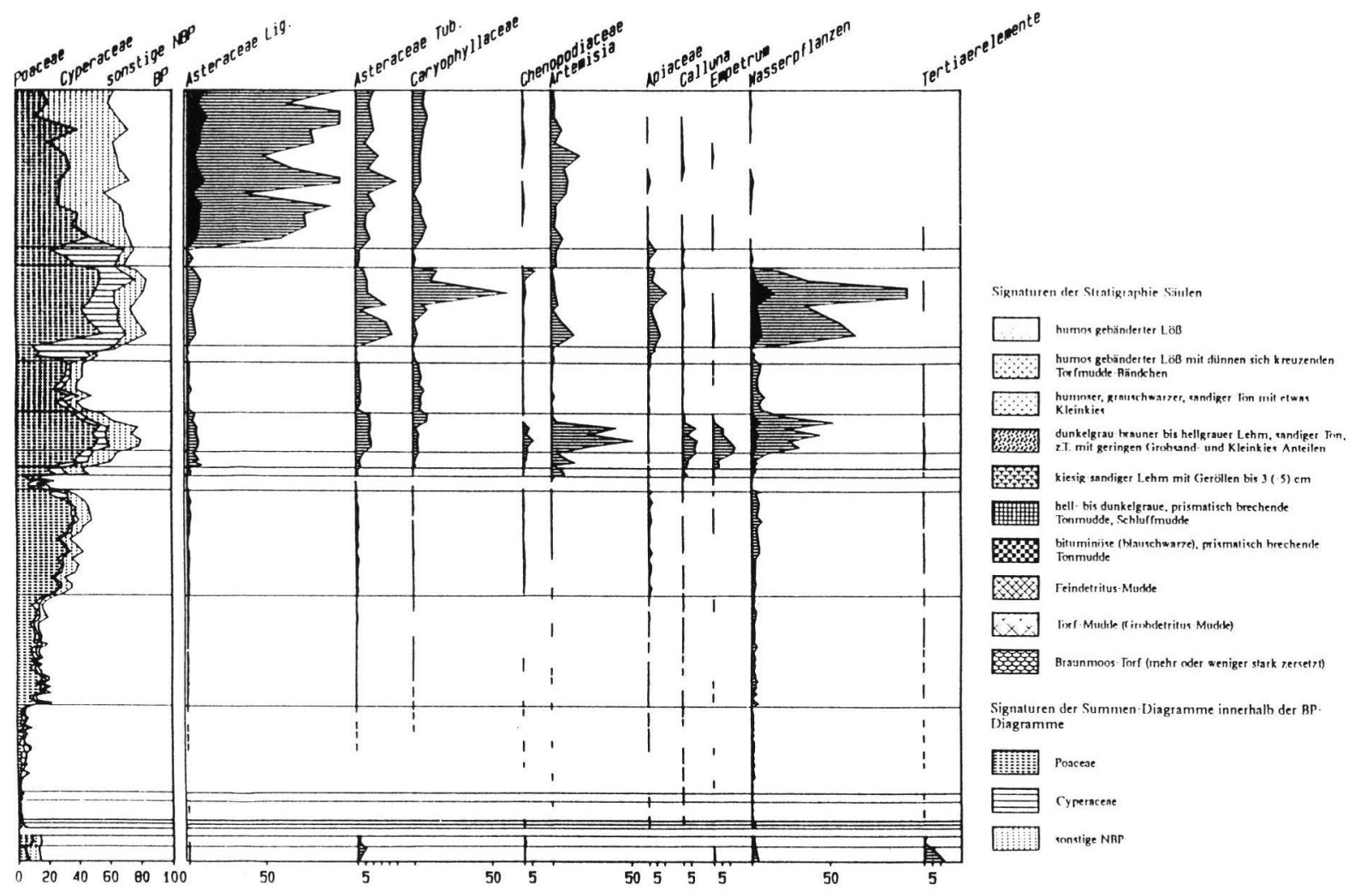

Corylus. (Mit freundlicher Genehmigung durch F. Bittmann) (Included by kind permission of F. Bittmann)

verdrängt und gegen Ende der Carpinus-Eichenmischwald Phase herrschten meso-oligotrophe Bedingungen im Gewässer vor.

Die Pinus Phase (lokale Pollenzone 8)

Während der Pinus-Phase zeigt sich eine lückige, waldtundrenartige bis waldfreie Vegetation; es ist mit kaltem Klima des beginnenden Glazials zu rechnen. Die starke Dominanz von Pinus im Pollenspektrum dürfte auf das lokale Vorkommen dieses starken Pollenproduzenten am Rande des zu dieser Zeit vollständig verlandeten Gewässers zurückgeführt werden.

Das Mülheim I-Stadial (lokale Pollenzonen 9-10)

Durch die anhaltende Klimaverschlechterung kommt es während dieser Phase zur vollständigen Entwaldung der Landschaft. Von jetzt an herrscht eine Tundravegetation vor. Gegen Ende des Mülheim I-Stadials entwickelt sich wiederum ein Gewässer.

Das Kettig Interstadial (lokale Pollenzone 11) Für interstadiale Klimaverhältnisse während des Kettig Interstadials spricht die Zunahme des BP-Anteils (vor allem Eiche und Fichte), sowie der Rückgang der Tundrenelemente. Als Ergebnis einer erhöhten Produktionsrate an organischem Material, aufgrund gemäßigteren Klimas, kann auf ein weite- res Trockenfallen des Gewässers geschlossen werden.

Das Mülheim II-Stadial (lokale Pollenzone 13)

Das Mülheim II-Stadial schließt die paläobotanisch untersuchte Sequenz nach oben ab. Gekennzeichnet durch völlige Waldlosigkeit zeigt die Vegetation nun einen tundraartigen Charakter. Im Laufe dieser Phase verbesserte sich das Klima wiederum, jedoch wesentlich schwächer als während des Kettig-Interstadials. Am Übergang der lokalen Pollenzonen 13 und 14 kommt es zu einer plötzlichen Vegetationsveränderung. Während zunächst kalte und feuchte Tundrabedingungen herrschten, lassen sich nun Arten nachweisen, die als typisch für eine kalte und trockene Steppenlandschaft angesehen werden können. Dieser plötzliche Wechsel könnte einen Hiatus unbekannter Dauer anzeigen.

\section{Gewässer und Umweltrekonstruktion}

Die Korrelation von Grabungs- und Pollenprofilen am Seeufer zeigte, daß die Sedimente während der lokalen Pollenzonen 6 und 7 der Carpinus-Eichenmischwald-Phase abgelagert wurden. Aus dieser Korrelation kann, zusammen mit Hinweisen durch die vertikale Verteilung der archäologischen Funde, 
Schicht IIta

(Pollenzone 6/7a des Kâricher Interglazials)
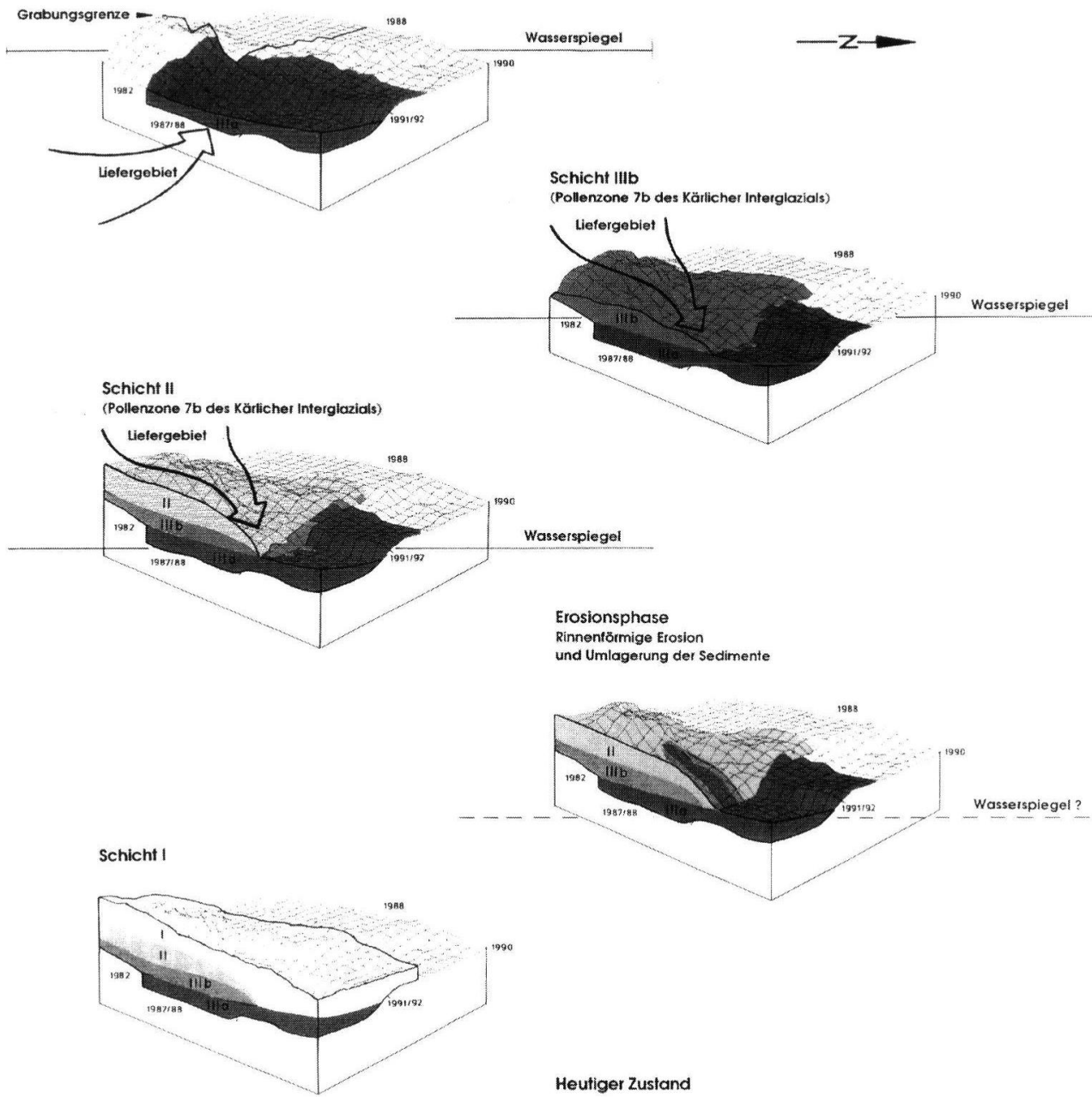

Heutiger Zustand

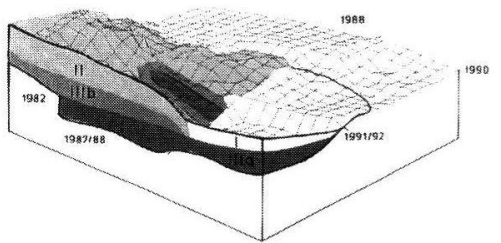

Abb. 4: Schematische Rekonstruktion zur Genese des Fundplatzes Kärlich-Seeufer.

Fig. 4: Schematic reconstruction of site formation processes at the Kärlich-Seeufer site.

auf die Gewässer- und Umweltsituation zum Zeitpunkt der Fundschichtgenese rückgeschlossen werden (Abb. 4).

Nach dem Klimaoptimum des Kärlich-Interglazials wurde zunächst die Schicht IIIa während der Pollenzonen 6 und $7 \mathrm{a}$ in den Tümpel eingeschwemmt. Die gute Pollenführung legt nahe, daß die Sedimente offenbar zunächst unterhalb der Wasseroberfläche zur Ablagerung kamen.

Die klimatische Abkühlung schreitet voran, der Anteil kaltzeitlicher Florenelemente nimmt zu. Dadurch kommt es zur Auflichtung der Bewaldung. In der zeitlichen Folge (Pollenzone $7 b$ ) gelangt die Schicht IIIb in den Tümpel. Die Pollenführung läßt auch hier die Ablagerung der Debrite unter Wasser plausibel erscheinen. Erst gegen Ende der Phase 
setzt die Austrocknung des Gewässers ein und die Uferlinie wandert in nördliche Richtung. Die Schicht II wurde offenbar gegen Ende der Phase $7 b$ abgelagert. Danach kam es zur partiellen Erosion der Debrite, die zur rinnenförmigen Abtragung der Schichten IIIb und II im mittleren Bereich der Grabungsfläche führte. Da Schicht I durch das Pollenprofil nicht erfaßt wurde, bleibt ungeklärt, wann es zur Ablagerung dieser Sedimente kam. In jedem Fall muß die Sedimentation nach der Ablagerung der Schicht II stattgefunden haben.

Offenbar wurden diese Sedimente durch Erosion nahezu vollständig abgetragen und konnten sich nur noch im hangabwärts gelegenen Flächenteil erhalten (Abb. 4).

Da die fundführenden Sedimente trotz ihrer Bildung durch Hangabspülungen einen recht lückenlosen pollenanalytischen Nachweis zeigen, muß von einer mehr oder weniger kontinuierlichen Ablagerung der Debrite ausgegangen werden. Wie später erläutert wird, wurde offenbar zumindest der Großteil des archäologischen Fundgutes zusammen mit den Debriten in den Tümpel eingeschwemmt.

\section{Die geochronologische Position der Fundstelle}

Paläontologische Arbeiten zu Kleinsäugern aus dem Abschnitt G des Kärlicher Hauptprofils (V. Kolfschoten 1990) legen nahe, daß die Fundstelle Kärlich-Seeufer jünger sein muß als das Interglazial IV des Cromer-Komplexes im Sinne der holländischen pleistozänen Stratigraphie (ZAGWIJN 1985). So wird der Abschnitt G biostratigraphisch der "Arvicola terrestris cantianasorex (Drepanosorex) sp. concurrent range-subzone" zugeordnet, die in das Cromer IV-Interglazial und an den Beginn der Elsterkaltzeit gestellt wird (V. KOLFSCHOTEN 1990).

Nach BitTMann (1991) kann der pollenanalytische Nachweis am Seeufer nur mit dem zweiten Optimum des Cromer-zeitlichen Interglazials von Bilshausen, Niedersachsen (MülLER 1965, 1992) gleichgesetzt werden und läßt sich weder mit dem Holstein noch mit dem Eem korrelieren. Wie die Analyse laminierter Seesedimente zeigt, dauerte die sogenannte Ruhme-Warmzeit von Bilshausen mehr als 25000 Jahre. Die Warmzeit wird von einem starken Klimarückschlag unterbrochen und die interglaziale Vegetation wurde durch einen Kiefern-Birkenwald ersetzt.

Nach BitTmann ist diese Situation mit den Kärlicher Nachweisen vergleichbar. Die interglaziale Molluskenfauna unterhalb des Brockentuffs könnte dem ersten klimatischen Optimum des Ruhme-Interglazials entsprechen. Während eines Klimarückschlages müßte dann der Boden, der die Molluskenfauna enthielt, umgelagert worden sein. Zu Beginn des zweiten Klimaoptimums wäre dann der Brockentuff eruptiert. Vereinzelte Makroreste von Acer campestre und Cornus mas, die an der Basis des Brockentuffs gefunden wurden, dienen hier als Beleg für die Eruption während einer interglazialen Phase (ScHIRMER 1990; BITTMAnN unveröffentlichte Daten). Entsprechend der palynologischen Ergebnisse repräsentiert die Pollenabfolge aus den Mudden, oberhalb des in die Depression umgelagerten Brockentuffs, das zweite Optimum des Kärlich-Interglazials. So schlüssig diese Deutung von seiten der Palynologie sein mag, die Interpretation ist nicht unumstritten. Aus geologischer Sicht kann nicht ausgeschlossen werden, daß der Boden, der die interglaziale Molluskenfauna enthielt, durch periglaziale Prozesse umgelagert wurde. In der Konsequenz müßten dann zwei unabhängige Interglaziale postuliert werden. Ein Interglazial unterhalb des umgelagerten Brockentuffs würde durch die interglaziale Molluskenfauna belegt, ein weiteres würde oberhalb des umgelagerten Brockentuffs durch Mudden mit interglazialer Pollenabfolge repräsentiert (GAUDZINSKI 1995a).

Von welcher Dauer der Hiatus zwischen dem umgelagerten Boden unterhalb des Brockentuffs und dem Brockentuff selber war, muß bis heute offen bleiben. Zusammenfassend lassen die biostratigraphischen und palynologischen Resultate plausibel erscheinen, daß der Fundplatz einer Warmzeit über dem Cromer-Komplex jedoch nicht dem Holstein (sensu stricto) zugeordnet werden kann.

Vom sedimentologisch-pedologischen Standpunkt aus läßt sich lediglich ein terminus ante quem zu Stadium 7 der marinen Sauerstoffisotopenkurve postulieren. Über dem fundführenden Horizont des Kärlicher Seeufers wurden kaltzeitliche Sedimente abgelagert. Darin ist als gut entwickelter Bt-Horizont einer Parabraunerde ausgebildet; Relikt einer interglazialen Bodenbildung eemzeitlichen Alters. Die Sedimentabfolge wird durch Ablagerungen abgeschlossen, die als weichselzeitlicher Löß interpretiert werden (GAUDZINSKI et al. 1995).

Physikalische Datierungsmethoden geben einen weiteren Anhaltspunkt für das Alter der Fundstelle. Der Brockentuff, im Liegenden der fundführenden Sedimente, war durch ${ }^{40} \mathrm{AR} /{ }^{39} \mathrm{AR}$ Lasereinzelkristalldatierung auf $396 \pm 20 \mathrm{ky}$ BP datiert worden. Dieses Datum wurde mit dem Sauerstoffisotopenstadium 11 korreliert (v. D. BOGAARD et al. 1989).

Die vorliegenden Ergebnisse sprechen am ehesten für eine Zuordnung des Platzes in die 018-Stadien 11 oder 9 der marinen Sauerstoffisotopenkurve.

\section{Das lithische Material}

Die Analyse des lithischen Materials wird am Fundplatz Kärlich-Seeufer durch eine Reihe von Faktoren erschwert, die mit der problematischen Identifizie- 
rung der Artefakte in Zusammenhang stehen. Geofakte, durch natürliche Prozesse zersprungene Steine, die die gleichen Merkmale wie Artefakte zeigen, sind seit langem bekannt (Mortelmans 1947, Clark 1958). Im speziellen Fall des Kärlicher Seeufers spielen „Tephrofakte“ (Bosinski et al. 1980: 310) eine große Rolle. Dabei handelt es sich um durch vulkanische Tätigkeit zerschlagene Steine. In Kärlich gilt der Brockentuff als Lieferant für diese „Tephrofakte". Bei der Eruption des Vulkans, der den Brockentuff lieferte, wurden devonische Schiefer, teritärer Ton, aber auch Lösse sowie Rhein- und Moselschotter durchschlagen. Alle diese Komponenten bilden Bestandteile des Brockentuffs.

Im fundführenden Sedimentpaket findet sich umgelagertes Material aus dem Brockentuff, darunter angeschlagene Rhein- und Moselschotter. Diese Stücke zeigen keine Spuren thermischer Einwirkung, sondern "Schlagmerkmale" in Form von Bulben, Auftreffpunkten und Spaltflächen. Die Differenzierung zwischen Artefakten und Naturprodukten ist somit eines der Kernprobleme bei der Analyse der Steingeräte. Erschwerend kommt hinzu, daß bei der Steingeräteherstellung Rohmaterialien Verwendung fanden, die auch im Brockentuff auftreten und die Schlagmerkmale nur ungenau erkennen lassen, wie devonischer Quarzit und Quarz.

Bemüht objektive Unterscheidungskriterien zur Abgrenzung von Artefakten und Tephrofakten zu erkennen, analysierte KulEmeYer (1988) den Fremdgesteinsanteil innerhalb des fundführenden Sediments im Vergleich zum Brockentuff.

Eine klare Abgrenzung zwischen Artefakten und Tephrofakten konnte trotz dieser Bemühungen nicht vorgenommen werden.

Für die Ausgrabungsarbeiten blieb dieser Aspekt nicht ohne Konsequenzen. Von 1982 an wurde das Steinmaterial systematisch aus Viertel-Quadratmetern, in 10-cm-Abhüben geborgen. Aus diesem Material wurden die Artefakte nachträglich ausgelesen. Die endgültige Auswahl der Steingeräte wurde von der Verfasserin vorgenommen. Durch die Kombination verschiedener Merkmale (wie z. B. Größe, Form, Rohmaterial, Schlagpunkt, Schlagfläche,

Tab. 1: Steingeräteinventar vom Fundplatz KärlichSeeufer $(n=146)$

\begin{tabular}{|lrl|}
\hline unmodifizierte Abschläge & $41,1 \%$ & $(\mathrm{n}=60)$ \\
Absplisse & $6,2 \%$ & $(\mathrm{n}=9)$ \\
Trümmerstücke & $2,0 \%$ & $(\mathrm{n}=3)$ \\
Abschlaggeräte & $31,5 \%$ & $(\mathrm{n}=46)$ \\
retuschierte „Stücke“ & $5,5 \%$ & $(\mathrm{n}=8)$ \\
bifaziell bearbeitete Stücke & $6,2 \%$ & $(\mathrm{n}=9)$ \\
Kerne & $7,5 \%$ & $(\mathrm{n}=11)$ \\
\hline
\end{tabular}

Schlagnarbe, Schlagrichtung, Ausbildung der Ventralfläche) erwiesen sich die Stücke als artifiziell (GAUDZINSKi 1995a).

Insgesamt umfaßt das Inventar 146 Stücke und glieder sich wie folgt:

Als Folge der Auslese ist das Steingeräteinventar von einer starken Bearbeitungsselektion geprägt. Diese findet in der qualitativen und quantitativen Zusammensetzung, z. B. im hohen Anteil an retuschierten Formen und im nahezu vollständigen Fehlen von Trümmerstücken Ausdruck.

Als Rohmaterial zur Herstellung der ausgelesenen Artefakte wurde, mit einem Anteil von $55 \%$, in der Hauptsache devonischer Quarzit verwendet. Steingeräte aus Quarz sind mit ca. $28 \%$ am Inventar beteiligt und Artefakte aus gut spaltbaren Materialien wie Tertiärquarzit, Kieselschiefer und Hornstein treten nur zu ca. $17 \%$ auf. Die meisten Rohmaterialien sind lokaler Herkunft und stammen, nach heutiger Kenntnis, aus Distanzen von bestenfalls $4 \mathrm{~km}$. Zum Zeitpunkt der Besiedlung lagerte der Rhein in der Nähe der Fundstelle ausgedehnte Schotterfelder ab, die als Beschaffungsquelle ebenso in Betracht kommen wie Rhein- und Moselschotter aus dem älteren Teil des Quartärs. Auch diese können in unmittelbarer Nähe der Fundstelle angetroffen werden. Weiterhin scheint die Entnahme von Geröllen aus dem Brockentuff, also aus dem Bereich des Fundplatzareals plausibel (FLoss 1994). Ein Schaber aus Tertiärquarzit (Abb. 5: 1) primären Vorkommens, weist auf das maximale Einzugsgebiet hin (Floss 1994). Die nächstgelegenen, bekannten Vorkommen von Blockfeldern finden sich heute ungefähr 3 bis $4 \mathrm{~km}$ nordöstlich der Fundstelle bei Saffig.

Insgesamt ist das Kärlicher Steingeräteinventar einfachen Charakters. Sowohl einfache unmodifizierte Abschläge als auch Abschlaggeräte sind durch einen hohen Anteil an Cortex und/oder Naturtrümmeroberflächen gekennzeichnet. Interpretierbare Dorsalflächenmuster treten selten auf und der überwiegende Anteil an Stücken zeigt dorsal bestenfalls gerade drei Negative. Die meisten Schlagflächen der Abschläge sind mit Rinde bedeckt und/oder zeigen Naturtrümmeroberflächen. Unter den Abschlaggeräten dominieren einfache Schaber, deren Arbeitskanten zumeist eine kontinuierliche, durchlaufende Retuschierung zeigen.

Die detaillierte vergleichende Analyse von unmodifizierten Abschlägen und Abschlaggeräten läßt Unterschiede zwischen beiden Gruppen erkennen. So zeichnen sich die unmodifizierten Abschläge häufig durch lateral gelegene Siretbrüche aus, die bei den Abschlaggeräten selten sind. Modifizierte Abschläge tragen lateral zumeist eine gerade oder konvexe Arbeitskante.

Weitere Unterschiede zwischen beiden Gruppen zeigen sich in der Anzahl der Dorsalflächennegative 


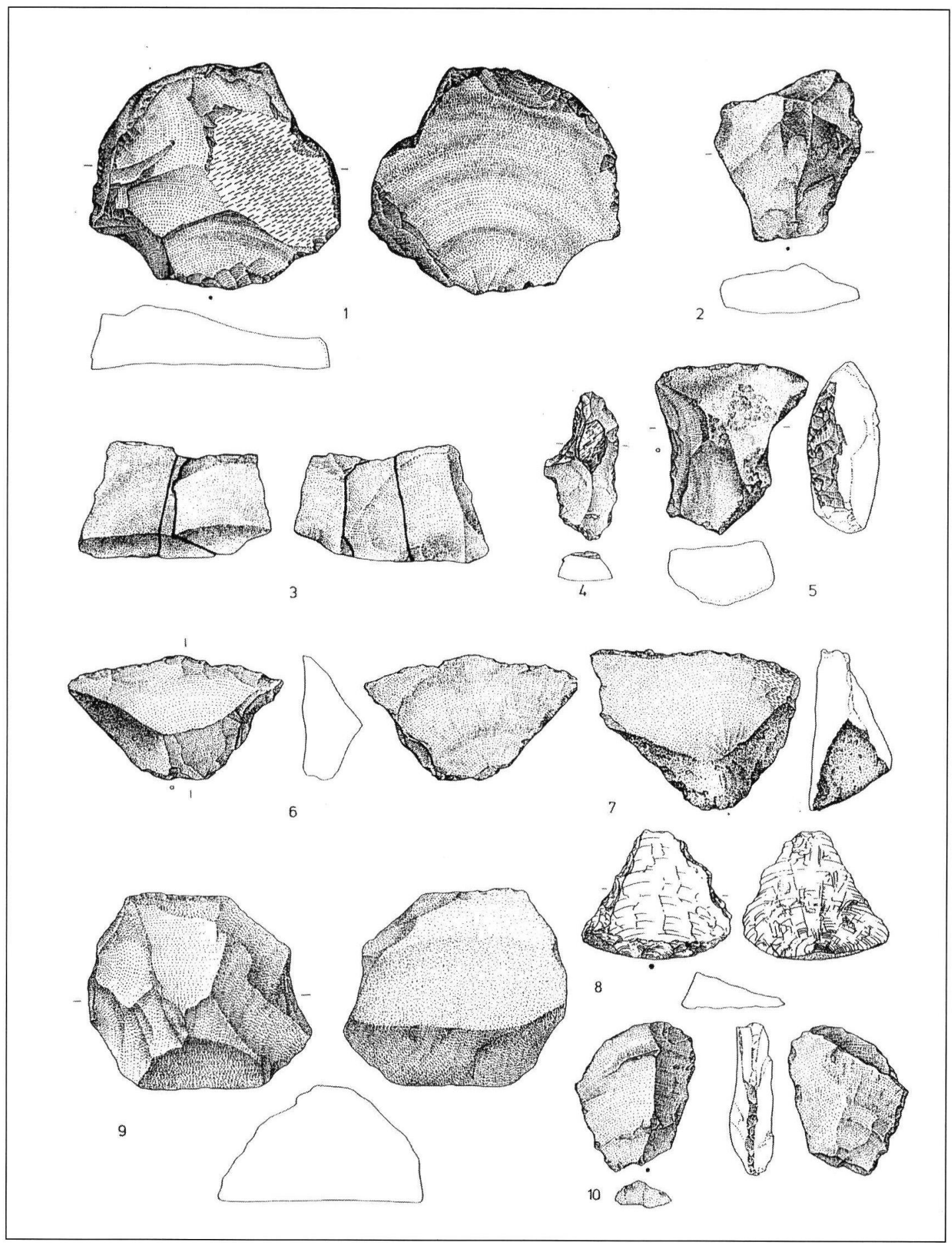

Abb. 5: Artefakte vom Fundplatz Kärlich-Seeufer. 1) Schaber aus Tertiärquarzit, 2) Abschlag mit retuschierter Kante aus devonischem Quarzit, 3) Zusammenpassung dreier unmodifizierter Abschläge aus devonischem Quarzit, 4) Abschlag aus Tertiärquarzit mit Holzrest, 5) retuschiertes „Stück“, 6, 7) Schaber aus devonischem Quarzit, 8) retuschierter Quarzabschlag, 9) Kern aus devonischem Quarzit, 10) Schaber aus Tertiärquarzit. $M=1: 1$

Fig. 5: Artefacts from the Kärlich-Seeufer site. 1) scraper, Tertiary quartzite, 2) retouched flake, Devonian quartzite, 3) refitting of three unmodified flakes, Devonian quartzite, 4) flake with wooden remain, Tertiary quartzite, 5) retouched "piece", 6, 7) scraper, Devonian quartzite, 8) retouched flake, Quartz, 9) core, Devonian quartzite, 10) scraper, Tertiary quartzite. Scale 1:1 
und bei den Schlagflächen. In der Gruppe der Abschlaggeräte ist der Anteil an Stücken mit 1-2 Negativen wesentlich höher als bei den unmodifizierten Stücken. Die Ursache hierfür könnte ebenfalls in der Bearbeitungsselektion liegen. Der Anteil an mit Rinde oder Naturtrümmeroberflächen bedeckten Schlagflächen liegt bei den Geräten um 25\% niedriger als bei den unmodifizierten Abschlägen. Doppelt so hoch ist dafür der Anteil an Stücken mit punktförmiger Schlagfläche. Diedrische Schlagflächen treten ausschließlich bei den Abschlaggeräten auf.

Der einfache Charakter des Abschlagmaterials findet sein Pendant in den Kernen (Abb. 5: 9). Einfache unifazielle Kerne, deren Oberflächen aufgewölbt zugerichtet und deren Unterseiten von Rinde oder natürlichen Spaltflächen charakterisiert werden, dominieren. Bifaziell bearbeitete Kerne treten seltener auf. Generell wurde deren Unterseite zu einem wesentlich geringeren Anteil zugerichtet als die Abbaufläche der Stücke. Die Unterseiten aller bifaziell bearbeiteten Kerne zeigen zumeist ebenfalls natürliche Spaltflächen und es ist anzunchmen, daß die Form der zur Bearbeitung genutzten „Rohlinge“ nur unwesentlich verändert wurde. Dies zeigen auch die bifaziell bearbeiteten Geräte wie Faustkeile (vgl. GAUDZINSKi 1994, Abb. 1 und 2) und Cleaver (vgl. GAUDZINSKI 1995b, fig. 57: 1 und KRÖGER et al. 1991, Abb. 9: 9), vor allem aber die retuschierten „Stücke“ (Abb. 5: 5). Hier wurden unmodifizierte „Rohlinge“ mit einfachen Arbeitskanten versehen. Die pragmatische Nutzung des Ausgangsmaterials läßt sich auch für die verwendeten Rohmaterialien nachvollziehen. So entspricht z. B. das Verhältnis der zur Steingeräteherstellung verwendeten Rohmaterialien der Häufigkeit des Auftretens dieser Gesteine innerhalb des lokalen Brockentuffs und damit wohl auch innerhalb der nahbei aufgeschlossenen Schotter, die als Rohmaterialbeschaffungsquelle angesehen werden können.

$\mathrm{Zu}$ einer relativ chronologischen Einordnung des lithischen Materials könnten lediglich zwei Faustkeile aus devonischem Quarzit herangezogen werden (vgl. z. B. Roe 1981; Gaudzinski 1994, Abb. 1 und 2). Allerdings hat die Faustkeilindustrie von High Lodge stichhaltige Hinweise dafür geliefert, daß an dem herkömmlichen Entwicklungsschema von Faustkeilen für den älteren Abschnitt des Paläolithikums nicht länger festgehalten werden kann (AsHToN et al. 1992).

Insgesamt verweisen Unterschiede in der Oberflächenerhaltung der Artefakte auf die Inhomogenität des Inventars. Einige Stücke aus devonischem Quarzit zeigen scharfe Kanten, die von einer ,frischen" Überlieferung der Steingeräte zeugen. Von diesen können andere aus gleicher Rohmaterialvarietät abgegrenzt werden, die durch stumpfere Kan- ten und geglättete Oberflächen charakterisiert werden.

Eine unterschiedlich lange Lagerung auf der Geländeoberfläche vor der Sedimentation der Artefakte, chemische, diagenetische Prozesse, aber auch unterschiedliche Einbettungsmilieus können für die dokumentierten Unterschiede verantwortlich sein. Darüber hinaus können Artefakte auch durch Transportvorgänge abradiert werden. Der ungewöhnlich frische Erhaltungszustand einiger Steingeräte verweist auf die syngenetische Ablagerung von Artefakten mit dem einbettenden Milieu.

Inwiefern die Abrasion verschiedener Steingeräte am Kärlicher Seeufer Ergebnis diagenetischer Prozesse ist, kann aufgrund der Inhomogenität der fundführenden Sedimente und der geringen Funddichte der Steinartefakte nicht eindeutig geklärt werden. Die Unterschiede in der Oberflächenerhaltung könnten jedoch am ehesten auf Unterschiede in der "Lebensgeschichte" von Teilen des lithischen Ensembles verweisen. Allerdings zeigen Steingeräte gleicher Machart auch, daß es sich nicht um ein willkürlich zusammengewürfeltes Inventar handeln kann. Vor allem unter den bifaziell bearbeiteten Stücken finden sich solche, die nach gleichem Prinzip bearbeitet wurden. Dazu zählen z. B. die bereits erwähnten Faustkeile sowie Cleaver aus devonischem Quarzit. Aber auch unter den Abschlaggeräten finden sich Schaber gleicher Machart, gefertigt aus gleicher Rohmaterialvarietät (z. B. Abb. 5: 6, 7). Die Zusammenpassung von drei einfachen unmodifizierten Abschlägen unterstreicht diesen Aspekt ebenfalls (Abb. 5: 3).

Abschließend sei auf einen patinierten Abschlag aus Teritärquarzit verwiesen, dem ein hölzerner Rest auf der Dorsalfläche anhaftet (Abb. 5: 4), der in früheren Beiträgen (vgl. z. B. KRÖGER et al. 1991) als Teil einer Schäftung interpretiert worden war. Hinweise sprechen gegen diese Interpretation. Der betreffende Abschlag stammt aus einem Bereich der Grabung, der durch erhebliche Eisenausfällungen charakterisiert ist. Aus gleichem Grabungsabschnitt stammen zahlreiche, oftmals vollständige, aber sicherlich nicht artifiziell modifizierte Gerölle unterschiedlicher Größe, denen ebenfalls Holzreste anhaften. Eisenausfällungen verbinden die Holzreste mit den Geröllen, die niemals in Verdacht standen, gerschäftet gewesen zu sein. Der betreffende Abschlag zeigt zahlreiche Bestoßungen, die von der Interaktion des Artefakts mit dem umgebenden Milieu zeugen, so daß das Anhaften des Holzrestes am ehesten auf diagenetische Prozesse zurückgeführt werden kann. Zusammenfassend muß das Artefaktmaterial vom Kärlicher Seeufer als selektiver Ausschnitt eines ursprünglich weitaus umfassenderen Ensembles betrachtet werden, das durch Artefakte mit unterschiedlicher "Lebensgeschichte“ bereichert worden 
sein könnte. Steingeräte sind aus älteren Abschnitten der Kärlicher Pleistozänabfolge bekannt geworden. Sichere Artefakte stammen aus dem Abschnitt G und wurden in verschiedenen Bereichen der Kärlicher Tongrube aufgesammelt (KulEMEYer 1988, VOLLBRECHT 1992). Es kann nicht ausgeschlossen werden, daß das lithische Ensemble z. B. durch Artefakte aus älteren Abschnitten der Kärlicher Tongrube bereichert wurde.

\section{Das faunistische Material}

Vom Fundplatz Kärlich-Seeufer stammen insgesamt 1162 Knochen und Knochenfragmente. Mit einem Anteil von $27 \%$ konnte nahezu ein Drittel des faunistischen Materials taxonomisch zugewiesen werden Das Faunenspektrum umfaßt folgende Arten:

Tab. 2: Faunengemeinschaft am Fundplatz Kärlich Seeufer. MNI (Minimum number of individuals), NISP (Number of identified specimens per taxon).* 161 kleine Elfenbeinfragmente blieben bei der Zählung unberücksichtigt.**) Das Rentier wird nur durch den basalen Teil einer Abwurfstange repräsentiert.

\begin{tabular}{|lll|}
\hline & MNI & NISP \\
Panthera leo ssp. & 1 & 3 \\
Elephas antiquus & 8 & $131^{*}$ \\
Equus sp. & 1 & 4 \\
Sus scrofa & 1 & 3 \\
Cervus elaphus & 1 & 18 \\
Rangifer sp. & $(1)^{* *}$ & 1 \\
Bos vel Bison & 4 & 26 \\
\hline
\end{tabular}

Die Fauna ist durch das Auftreten klimatisch anspruchsvoller Arten wie Elephas antiquus und Sus scrofa charakterisiert. Vor allem Elephas antiquus gilt als typisch interglaziales Faunenelement, weil die Art in warmzeitlichen Faunen Mitteleuropas häufig vertreten ist, in kaltzeitlichen Ensemblen hingegen fehlt (KurTÉN 1968).

Auch Sus scrofa wird gemeinhin als typischer Vertreter interglazialer Umweltverhältnisse betrachtet, obwohl die Gattung Sus auch aus kaltzeitlichen Faunengesellschaften bekannt geworden ist (DELPECH \& HeINTz 1976). Das Auftreten von Sus scrofa und Elephas antiquus spricht zunächst für eine bewaldete Umgebung und könnte somit auf einen warmzeitlichen Kontext verweisen. Außergewöhnlich ist indes der Nachweis von Rangifer sp. Rangifer tarandus ist im Neuwieder Becken erstmals aus saalezeitlichen Ablagerungen am Vulkan Schweinskopf bekannt geworden (TurNer 1989). Das Auftreten von Rangifer tarandus spricht im allgemeinen gegen einen interglazialen Kontext. Insofern könnte angenommen werden, daß das Kärlicher Geweihfragment als umgelagerter Sedimentbestandteil Eingang in die Faunenakkumulation fand. Allerdings korrespondiert der Beleg von Rangifer mit dem Auftreten kaltzeitlicher Florenelemente im pollenanalytischen Nachweis der Fundstelle. Zum Zeitpunkt der Ablagerung der fundführenden Sedimente war das klimatische Optimum der Warmzeit bereits überschritten. Eine stetige Abnahme der Bewaldung bzw. Entwaldung des Gebietes ist evident. Die Resultate der Pollenanalyse belegen das schwierig zu interpretierende Auftreten von Larix bereits an der Basis der Fundschicht. Larix tritt normalerweise erst sehr spät am Übergang zu Kaltzeiten auf (BITTMANN 1991).

Nachweise von der süddeutschen Fundstelle Rottenburg-Siebenlinden (STEPPAN 1993, HAHN et al. 1993) sowie von den Abris Bettenroder Berg IX und Abris Sphinx II, Lkr. Göttingen (mündl. Mitt. K. GroTE 1994) zeugen außerdem vom Auftreten des Rentiers in borealen und präborealen Zusammenhängen. Am Fundplatz Rottenburg-Siebenlinden tritt Rangifer tarandus zusammen mit einer Waldfauna auf. Inwiefern das Rentier am Fundplatz Kärlich-Seeufer, zusammen mit den anderen nachgewiesenen Arten eine homogene Faunengesellschaft bildete, kann abschließend nicht geklärt werden.

Die qualitative Erhaltung der Fauna taugt nicht zur Eingrenzung der geochronologischen Position der Fundstelle. Es kann weder geklärt werden, welche Panthera-Art durch das Faunenmaterial repräsentiert wird, noch ob es sich am Kärlicher Seeufer um coronates oder acoronates Rotwild handelt. Insofern bleibt die Frage nach dem pre- oder post-holsteinzeitlichen Charakter der Fauna ungeklärt.

Nur die Elefantenreste sollen im folgenden detailliert angesprochen werden.

\section{Elephas antiquus (FALCONER \& CAUTLEY, 1845)}

Reste von Elephas antiquus dominieren im Faunenmaterial des Kärlicher Seeufers. Vom Oberschädel haben sich mehrere Stoßzahnfragmente, darunter das distale Fragment eines jungen Individuums (Länge $16 \mathrm{~cm}$, Durchmesser an der breitesten Partie des Zahnes $47,0 \mathrm{~cm}$ [TuRner 1989]) sowie ein proximal leicht beschädigtes komplettes Stück eines erwachsenen Tieres (laterale Länge $231 \mathrm{~cm}$, größter Umfang proximal $57,0 \mathrm{~cm}$ [TURNER 1989]) erhalten. Drei weitere Stoßzähne sind wegen Konservierungsarbeiten z. Zt. unzugänglich. Aus dem Oberkiefer von Elephas antiquus lagen insgesamt 9 Molaren zur Bearbeitung vor, deren morphometrische Charakteristiken in der Tabelle 3 zusammengefaßt werden. Auf die detaillierte Beschreibung einzelner Molaren soll hier verzichtet werden, erwähnt sei jedoch, daß mehrere Zähne von ein und demselben Individuum stammen. So zeigt die Occulusalfläche des M2KäOI1 Merkmale des letzten Abkauungsgrades, während die Abrasionsmerkmale des M3Kä1 1/1 gering sind. Nur vier Molarlamellen waren zum Zeitpunkt des 
Tab. 3: Oberkiefermolaren von Elephas antiquus der Fundstelle Kärlich-Seeufer. (L) Länge, (B) Breite, (H) Höhe, (LA) Anzahl der Lamellen, (SD) Schmelzdicke, (LF) Lamellenfrequenz. Angaben in mm. Zur Beschreibung der Maße vgl. Maglio (1973: 8-13). *1 Die stratigraphische Zuweisung dieser Molaren zum fundführenden Sedimentpaket ist nicht gesichert, da die Stücke vor Grabungsbeginn geborgen wurden.

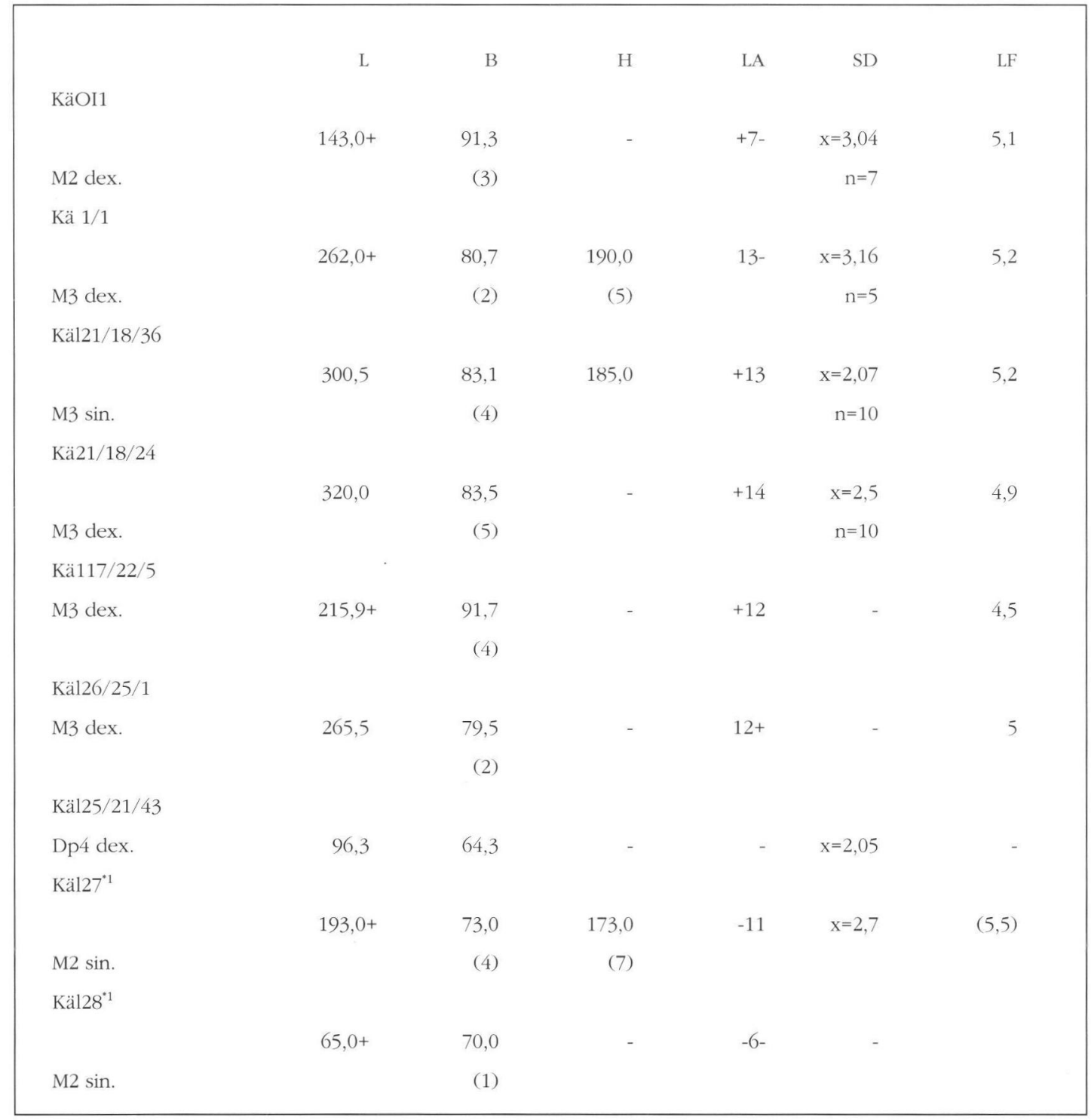

Todes dieses Tieres in Benutzung (Abb. 6). Auch die Occlusalflächen der Molaren KÄ126/18/36 und Kä121/18/24 (Abb. 7, Abb. 8) zeigen die gleichen Abrasionserscheinungen. Beide Zähne stammen wahrscheinlich ebenfalls von ein und demselben Tier.

Verwiesen sei auch auf den Molar Kä125/21/43 (Abb. 9), ein dp4 aus der rechten Oberkieferhälfte. Die Occlusalfläche dieses Zahnes zeigt ein fortgeschrittenes Stadium der Abnutzung. Alle erhaltenen Schmelzfalten sind zu einer Figur verschmolzen. Es hat sich eine nahezu glatte Kaufläche gebildet, der
Schmelz ragt kaum über Dentin und Zahnzement. Die Lamellen nehmen fast die gesamte Kaufläche ein und das Zwischenzement bildet nur noch einen schmalen Streifen. An diesem Molar läßt sich nur noch eine Wurzel beobachten, die übrige Zahnsubstanz ist resorbiert.

Weiterhin stammt vom Schädel der mediale Teil eines Oszygomaticum einer rechten Schädelhälfte.

\section{Unterkiefer}

Aus dem Unterkiefer lagen vier isolierte Molaren zur Bearbeitung vor. 


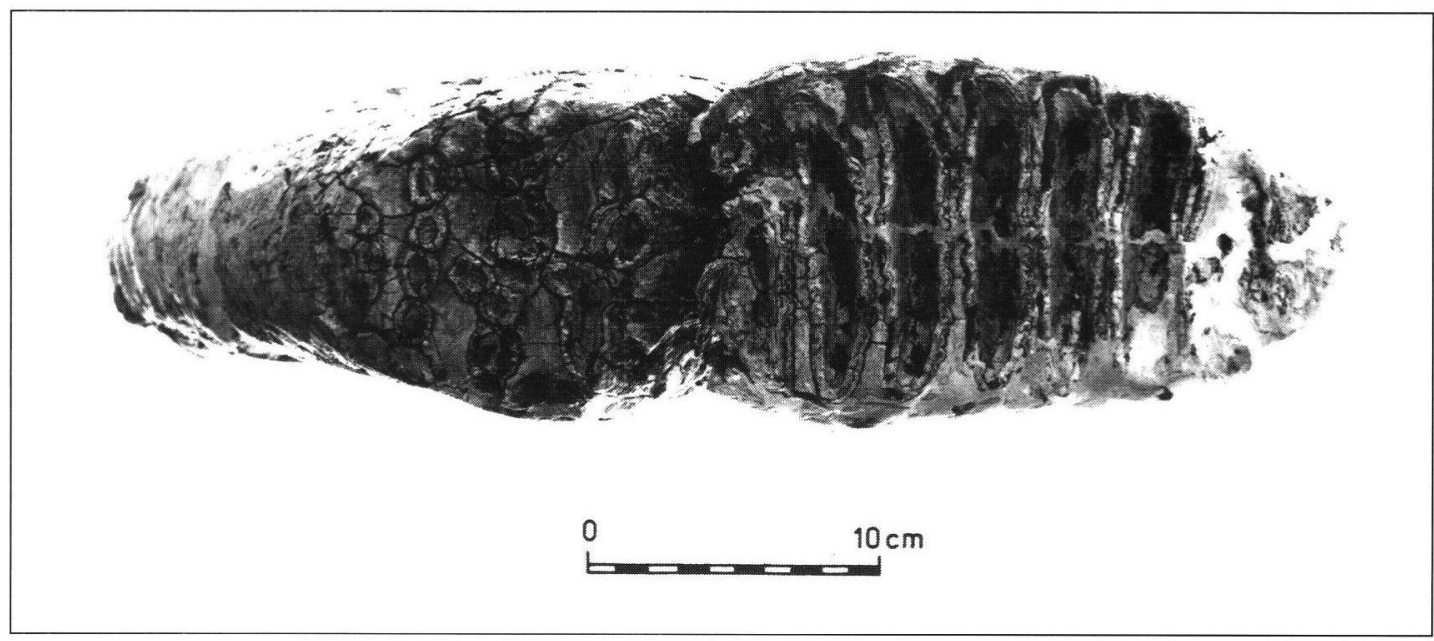

Abb. 6: Elephas antiquus. $\mathrm{M}^{2}$ dex. KäOI1 und $\mathrm{M}^{3}$ dex. Kä11/1 von occlusal.

Fig. 6: Elephas antiquus. $\mathrm{M}^{2}$ dex. KäOI1 and $\mathrm{M}^{3}$ dex. Kä11/1 occlusal views.

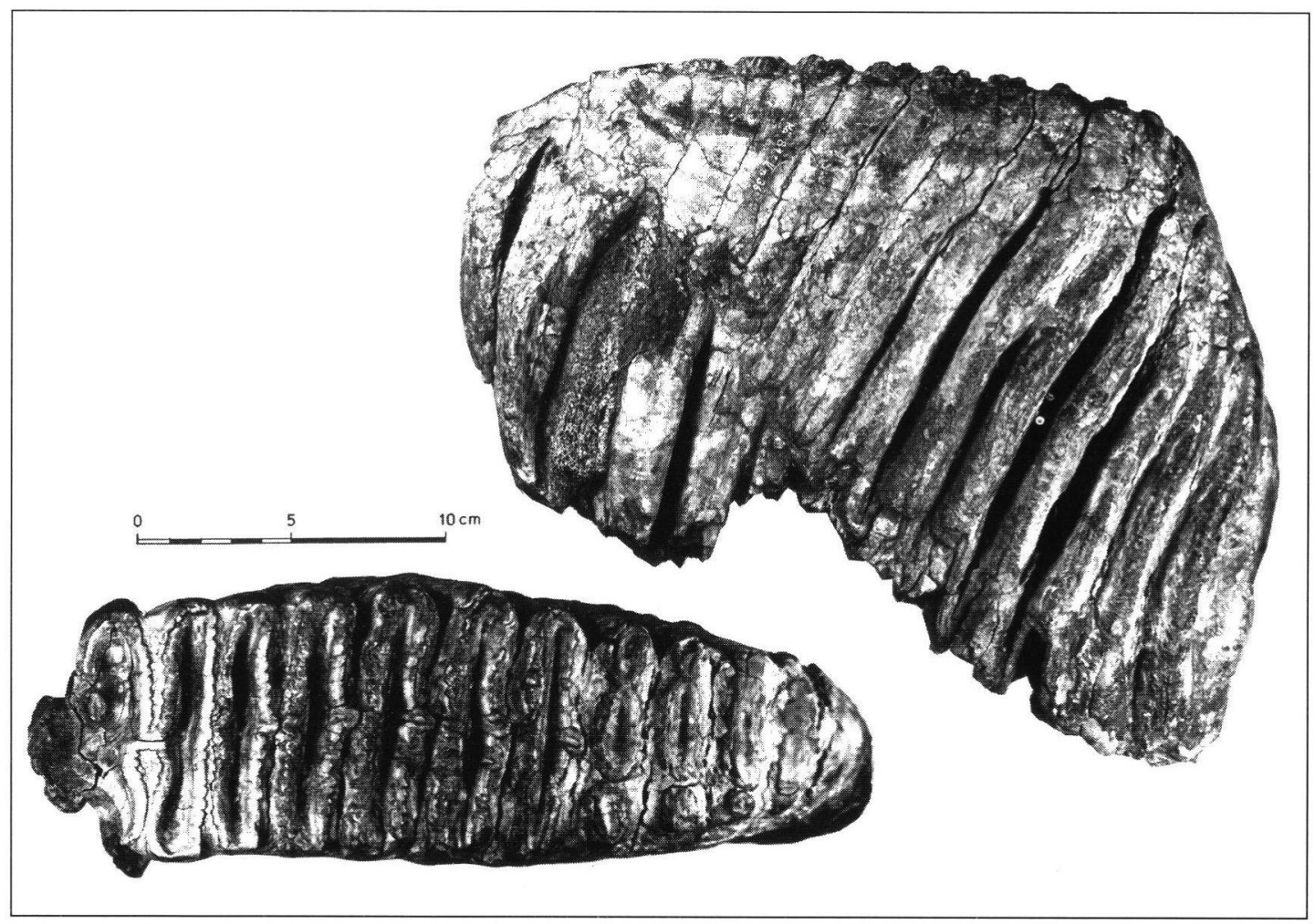

Abb. 7: Elephas antiquus. $\mathrm{M}^{3} \sin$. Kä121/18/36 von occlusal und lingual.

Fig. 7: Elephas antiquus. $\mathrm{M}^{3} \sin$. Kä121/18/36 occlusal and lingual views.

Außer isolierten Molaren liegt ein vollständiger Unterkiefer mit M3 sin. und dex. vor. Dieses Stück wird zur Zeit konserviert, die Vermessung der Molaren war insofern problematisch und es konnten nur einige Maße von einem der Zähne genommen werden (vgl. Tab. 4, Kä87/301). Zusammen mit den Ober- kiefermolaren Kä121/18/24 und Kä121/18/36 (Abb. 7, Abb. 8) repräsentiert dieser Fund ein Individuum. Auch in diesem Zusammenhang soll von einer detaillierten Beschreibung der Molaren abgesehen werden. Verwiesen sei lediglich auf den M3Kä124/21/60 (Abb. 10). Der Molar stammt aus der 


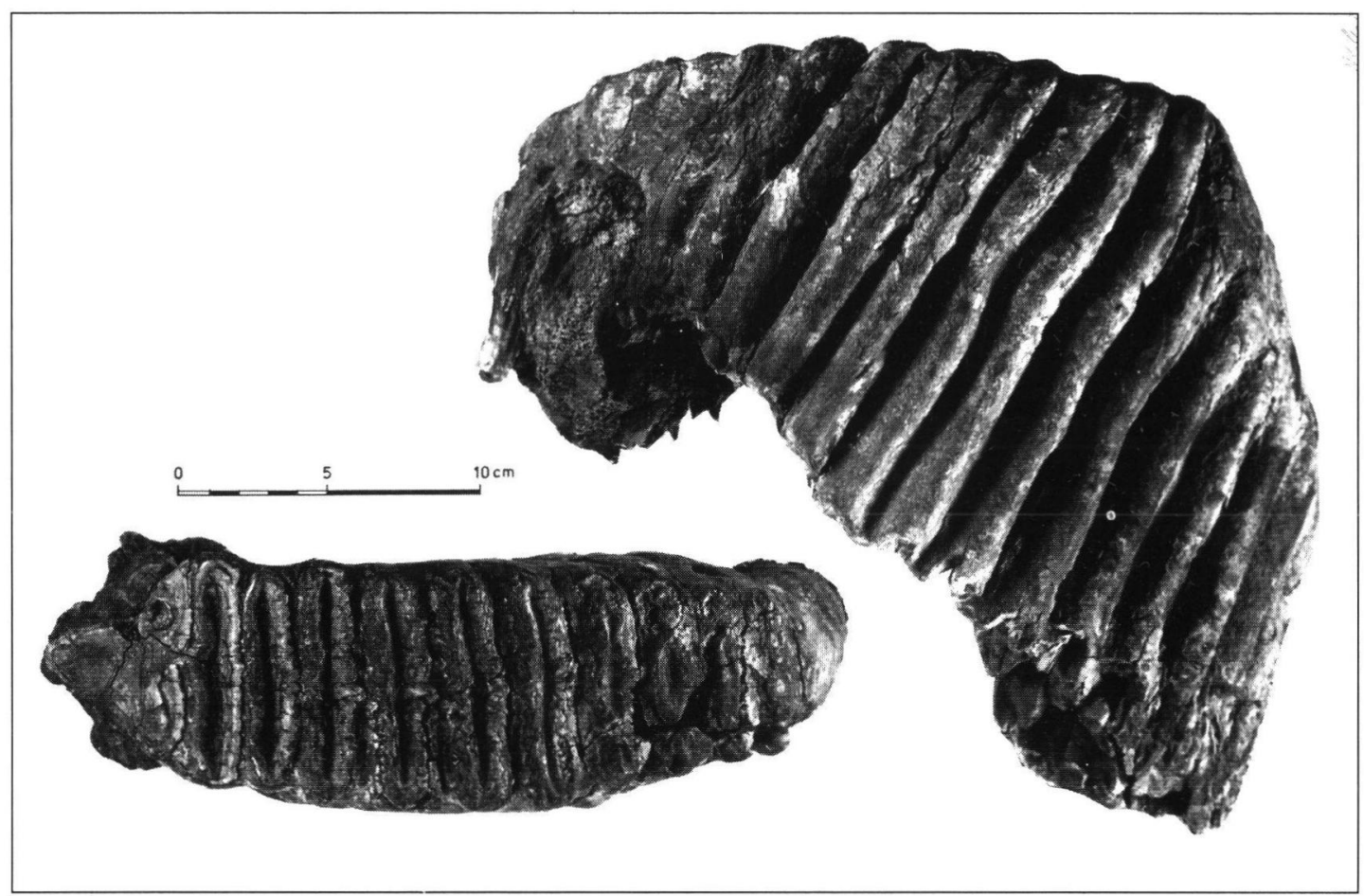

Abb. 8: Elephas antiquus. $\mathrm{M}^{3}$ dex. Kä121/18/24 von occlusal und buccal.

Fig. 8: Elephas antiquus. $\mathrm{M}^{3}$ dex. Kä121/18/24 occlusal and buccal views.

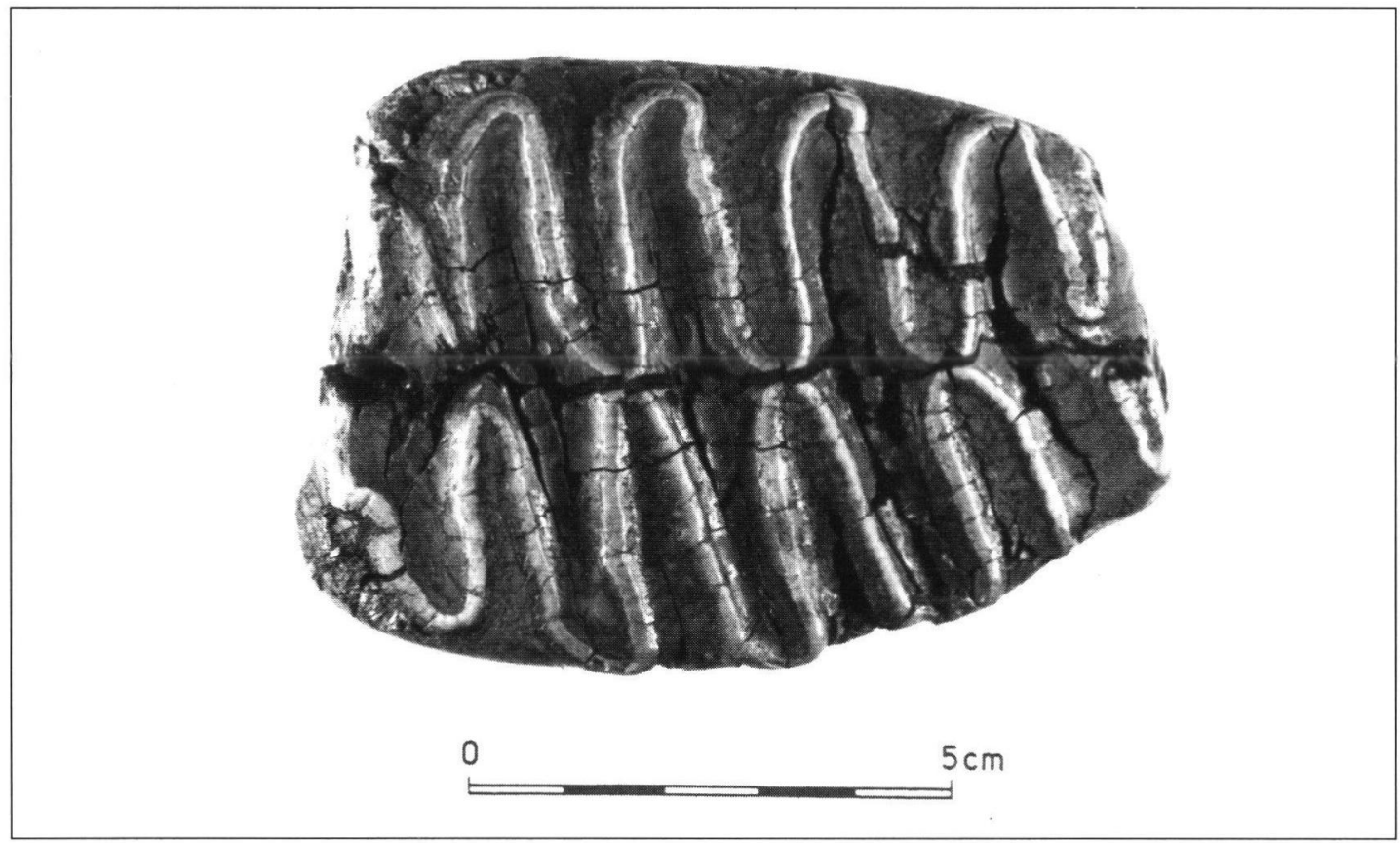

Abb. 9: Elephas antiquus. Dp4 Kä125/21/43 von occlusal.

Fig. 9: Elephas antiquus. Dp4 Kä125/21/43 occlusal view.

rechten Hälfte eines Unterkiefers und ist vollständig erhalten. Auf der Kaufläche zeigen die Lamellen III, IV und V Mittelzacken, die sowohl nach anterior als auch nach posterior gerichtet sind. Das posterior gelegene Ende der Kaufläche ist unter dem Deckzement verborgen. Der Zahnschmelz ist glatt und nur 
Tab. 4: Isolierte Molaren des Unterkiefers vom Fundplatz Kärlich-Seeufer. (L) Länge, (B) Breite, (H) Höhe, (LA) Anzahl der Lamellen, (SD) Schmelzdicke, (LF) Lamellenfrequenz. Angaben in mm. Zur Beschreibung der Maße vgl. MAGuIo (1973: 8-13) *1 Die stratigraphische Zuweisung dieser Molaren zum fundführenden Sedimentpaket ist nicht gesichert, da die Stücke vor Grabungsbeginn geborgen wurden.

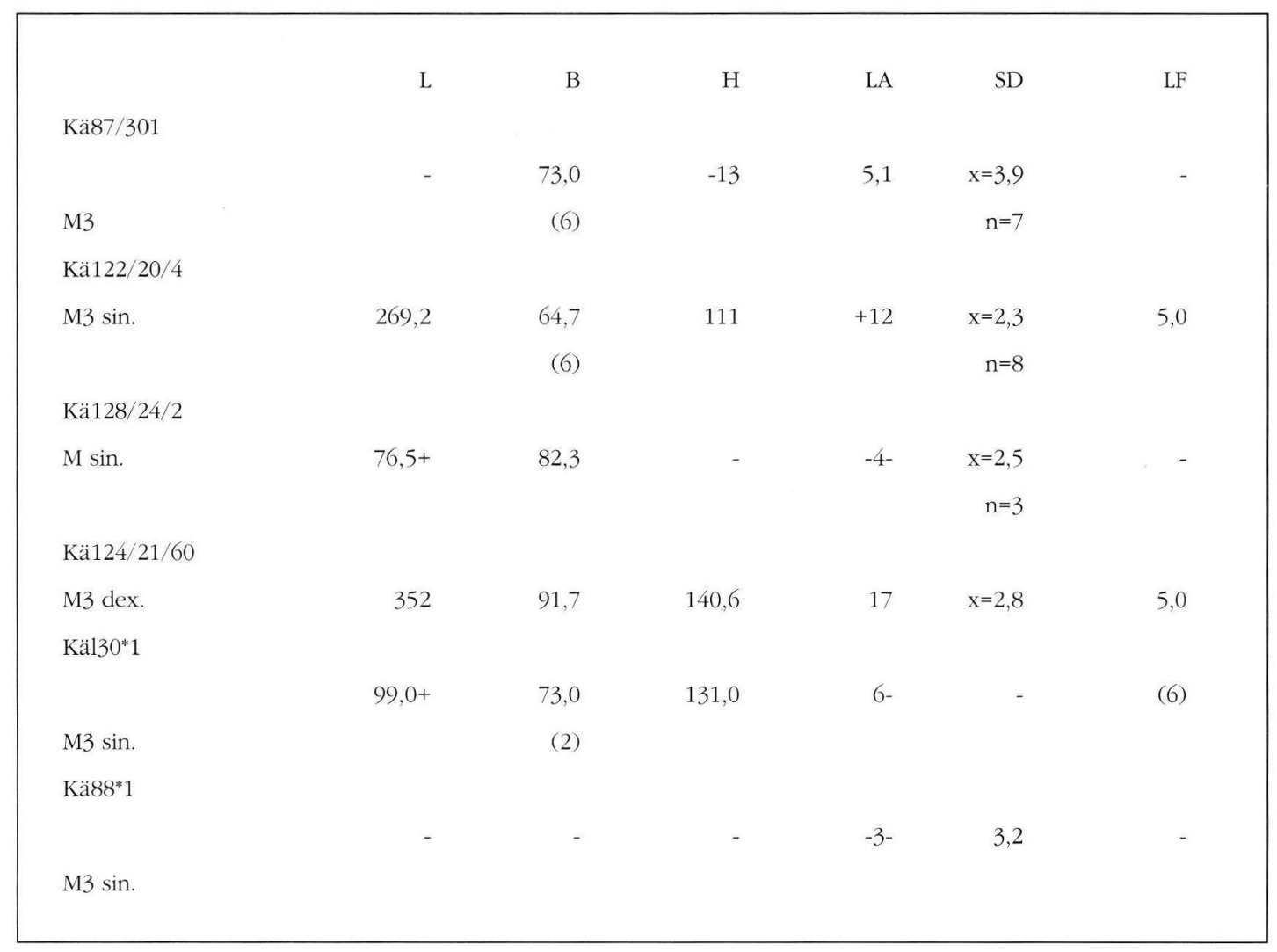

gelegentlich wenig geperlt. Die Wurzeln sind bis zur Lamellle VI nahezu geschlossen, ansonsten jedoch weit geöffnet. Auffallend ist eine Anomalie in der Stellung der anterior gelegenen Wurzelpartie. Im Bereich der Lamelle III und IV scheint die Wurzel partiell resorbiert. Die verbleibende Substanz ist als Wulst ausgebildet, dier sich beidseitig nach posterior auf die lingual und buccal gelegenen Flächen des Zahnes geschoben hat. Mit dieser Wurzelveränderung geht das starke Einziehen der anterior gelegenen Wurzel nach posterior einher. Die anomale Wurzelstellung könnte durch eine Verletzung mit nachfolgender verheilter Entzündung am Unterkiefer hervorgerufen worden sein.

An den Molaren vom Fundplatz Kärlich-Seeufer können häufig Hypoplasien beobachtet werden (vgl. Abb. 7). Die Ursache für Hypoplasien kann in Stoffwechselstörungen oder krankhaften Veränderungen des Zahnes liegen.

Da hypoplasieartige Rillen an Elephas antiquus-Molaren häufig beobachtet werden (GUENTHER 1978, 1989), muß offen bleiben, inwieweit es sich hier um eine pathologische Veränderung handelt.
Insgesamt fällt bei der morphologischen Betrachtung der Molaren vom Fundplatz Kärlich-Seeufer deren Robustheit auf. Es handelt sich um ein Merkmal, das durch vergleichende Analysen mit Molaren anderer mittel- und jungpleistozänen Fundstellen weiter verifiziert werden kann (GAUDZINSKI 1995a). Der Vergleich mit Elephas antiquus-Molaren anderer interglazialer Fundstellen wie Swanscombe (GB), Bilzingsleben (D), Steinheim (D) und eemzeitlichen Travertinen des Weimarer Stadtgebietes zeigte, daß die Kärlicher M3 sup. und inf. deutlich außerhalb der Spannbreite von Molaren anderer mittel- und jungpleistozäner Fundstellen liegen. Bei vergleichbarer Lamellenanzahl bzw. Lamellenfrequenz sind die Molaren vom Kärlicher Seeufer durch erheblich höhere Zahnlängen charakterisiert.

Stammskelett

Vom Stammskelett liegen zwei vollständige Cervicalwirbel sowie das Fragment eines weiteren Halswirbels vor. Weiterhin sind zwei Thoracalwirbel überliefert, zwei weitere Brustwirbel haben sich in 
fragmentiertem Zustand erhalten. Bei einem weiteren Fund, Kä123/24/16, handelt es sich um ein dorsales Fragment, das bis zum Ansatz des Wirbelkörpers erhalten ist. Die Epiphysenfuge zum Körper war zum Zeitpunkt des Todes dieses Tieres nicht verwachsen. Ein anderer Brustwirbel wird durch eine pathologisch deformierte Spina vertreten:

Tab. 5: Wirbel von Elephas antiquus vom Fundplatz Kärlich-Seeufer. $(\mathrm{GH})=$ Größte Höhe, $(\mathrm{GBd})$ Größte Breite dorsal, (GBv) Größte Breite ventral. Angaben in mm. * Funde ohne Inventarnummern. Vermessung nach v. d. Driesch (1976).

$\begin{array}{ll}\text { Cervicalwirbel } & \text { GH } \\ \text { Kä55/85/5 } & 277 \\ \text { Kä73/55/5 } & 293 \\ \text { Thoracalwirbel } & \\ \text { KäO.I.* } & 750 \\ \text { KäO.I.* } & 750\end{array}$

Die Cervicalwirbel sind in ihrer Höhe relativ niedrig. Vergleicht man die Höhe von Halswirbeln anderer Waldelefanten (wie z. B. Kiesäcker 72, Gröbern 1, Riano, Crumstadt und Gröbern II) zeigt sich, daß die Kärlicher Wirbel in ihrer Höhe am ehesten mit denen weiblicher Tiere verglichen werden können (vgl. Kroll 1991, Tab. 24-28).

Vom Becken haben sich insgesamt 4 Fragmente erhalten, die aus dem Bereich des Osiliums stammen. Der Rumpf wird weiterhin durch 7 Rippenbruchstücke mit einer Länge von $250 \mathrm{~mm}$ bis $820 \mathrm{~mm}$ vertreten. Vom Stylopodium ist ein stark beschädigtes Bruchstück eines distalen Femurs erhalten. Die Epiphyse war zum Todeszeitpunkt nicht verwachsen. Das Zeugopodium ist durch die Diaphyse einer linken Tibia belegt. Der Umfang beträgt $230 \mathrm{~mm}$ und könnte von einem jüngeren Tier stammen (vgl. Kroll 1991). Das Distalfragment einer rechten Fibula zählt ebenfalls zu den Stücken, die aus dem Bereich des Zeugopodiums erhalten sind. Bruchstücke zweier Fußwurzelknochen liegen aus dem Bereich des Autopodiums vor.

\section{Altersangaben}

Analog zu rezenten Elefantenpopulationen können auch für pleistozäne Elefanten Altersbestimmungen durchgeführt werden. Allerdings können Abrasionserscheinungen an Molaren und das Postcranialskelett nur Hinweise auf das Sterbealter der Tiere liefern. Die hohe Lebenserwartung der Elefanten (vgl.
HAYNes 1991), geschlechtsspezifische oder populationsspezifische Unterschiede beim Durchbruch der Molaren (HANKS 1969, FATTI et al. 1980) erschweren rezente Studien erheblich.

Laws Untersuchung (1966) beschreibt dreißig Altersklassen für $L$. africana, die durch das Fortschreiten von Eruption und Abrasion der sechs Zähne jedes Unterkiefers gekennzeichnet sind. Eine unpublizierte Studie befaßt sich ebenfalls mit Altersbestimmungskriterien anhand von Molaren (CRAIG zitiert in HAynes 1991). Haynes (1991) vergleicht die Ergebnisse beider Untersuchungen miteinander und zeigt, daß sich die Altersschätzungen für Zähne mit gleichen Abrasionsmerkmalen um bis zu 7 Jahre unterscheiden können. Da taxonomische, morphologische und ökologische Unterschiede zwischen $L$. africana und E. antiquus bestehen, liefern diese Studien in jedem Fall nur Anhaltspunkte für das Alter pleistozäner Elefanten.

Die Altersschätzungen, die nach den Maßgaben LAws (1966) und Craigs (vgl. Haynes 1991) für die Molaren vom Fundplatz Kärlich-Seeufer ermittelt wurden, werden in der folgenden Tabelle gegenübergestellt:

Tab. 6: Vergleich der Alterszuweisungen der Molaren von Elephas antiquus vom Fundplatz Kärlich-Seeufer nach Laws (1966) und Graig (vgl. Haynes 1991).

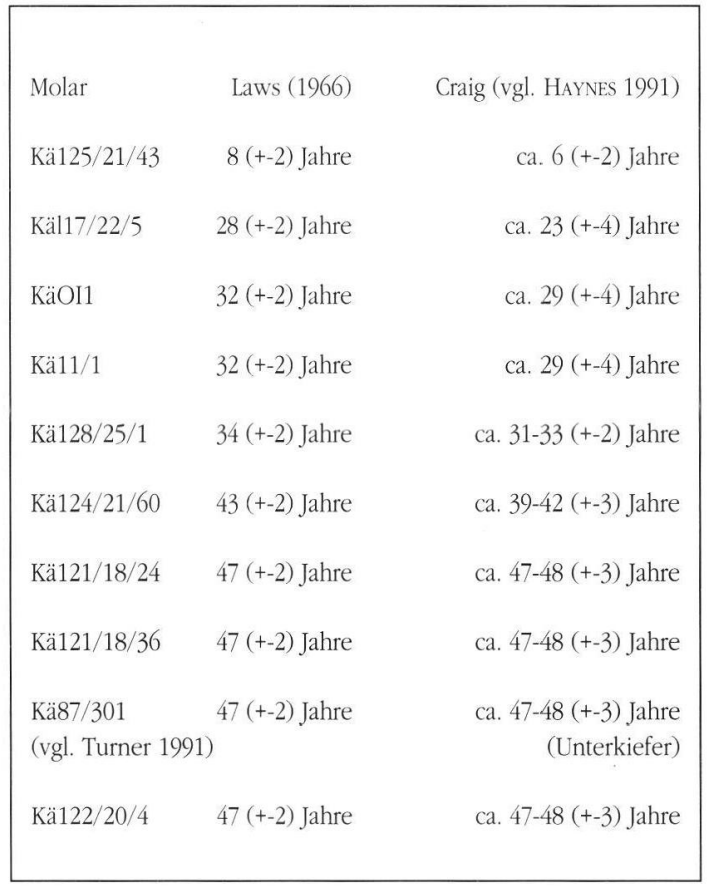

Altersbestimmungen anhand des Postcranialskelettes sind bei Elefanten ebenfalls schwierig. Der Zeitpunkt des Epiphysenverschlusses ist extrem variabel und von Geschlecht (HAYNES 1985), Gattung (ROTH 1984) und der Sozialstruktur der Tiere abhängig 


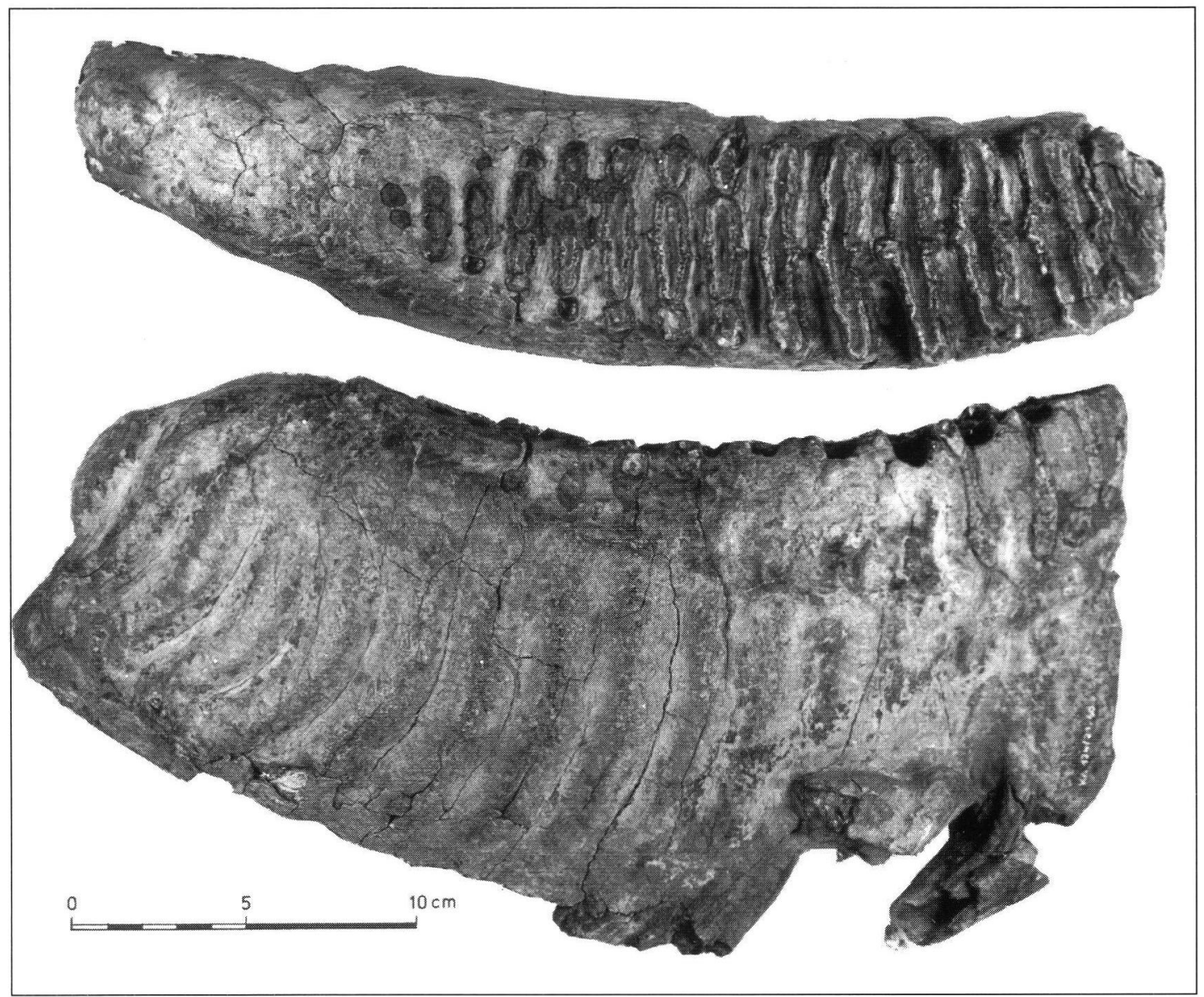

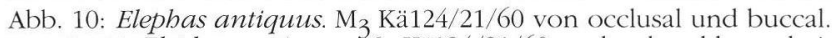

Fig. 10: Elephas antiquus. $\mathrm{M}_{3}$ Kä124/21/60 occlusal and buccal views.

(Haynes 1991). Grobe Richtlinien für den Zeitpunkt des Epiphysenverschlusses liegen zwar vor (z. B. HAYNES 1991, Tab. A 15), ermöglichen jedoch nur eine ungenaue Alterszuweisung.

Die übrigen am Kärlicher Seeufer vertretenen Tierarten werden nur durch wenige Fragmente überliefert. Nur Cervus elaphus und Bos/Bison sind durch mehr als 10 Elemente vertreten. Bei den Resten von Cervus elephus handelt es sich im wesentlichen um Geweihfragmente. Bos/Bison wird hauptsächlich durch Metapodien repräsentiert. Schädelfragmente, das vollständige Becken eines ca. 7jährigen männlichen Tieres sowie Wirbel sind ebenfalls belegt.

\section{Zur Taphonomie des Faunenmaterials}

Berücksichtigt man die komplexe Genese der fundführenden Sedimente durch "debris-flows", gilt es zunächst zu überprüfen, inwieweit die Faunenreste solche oder ähnliche Prozesse widerspiegeln. Dazu sollen zunächst die abiotischen Merkmale des Kärlicher Knochenensembles kurz angesprochen werden. Das Faunenmaterial ist durch unterschiedliche klimatische Oberflächenverwitterung gekennzeichnet. Es treten stark verwitterte (BEHRENSMEYER 1978, Stadium 5-6), mäßig verwitterte (BEHRENSMEYer 1978, Stadium 3-4) und unverwitterte Knochen zu nahezu gleichen Teilen auf. Diese Oberflächenveränderung ist unabhängig von der Tierart und ist an keine Größenfraktion gebunden.

Abrasionsmerkmale wurden ebenfalls qualitativ und quantitativ untersucht. Es dominieren stark abradierte Faunenreste; unabradierte bzw. mäßig abradierte Knochen (Abb. 11) treten jedoch ebenfalls auf (vgl. SHIPMAN 1981, fig. 5.7). Es läßt sich kein direkter Zusammenhang zwischen der Größe eines Knochens, dem Abrasionsgrad und der repräsentierten Tierart aufzeigen.

Der Großteil des taxonomisch determinierten Faunenmaterials ist, abgesehen von Langknochen des E. antiquus, mehr oder weniger vollständig erhalten, der Anteil an Schaftfragmenten von Langknochen gering. Knochenfragmente mit Spiralbrüchen treten mit nur 5 Stücken auf. Der Großteil des Fundmaterials ist durch starke Fraktionierung, in Form 


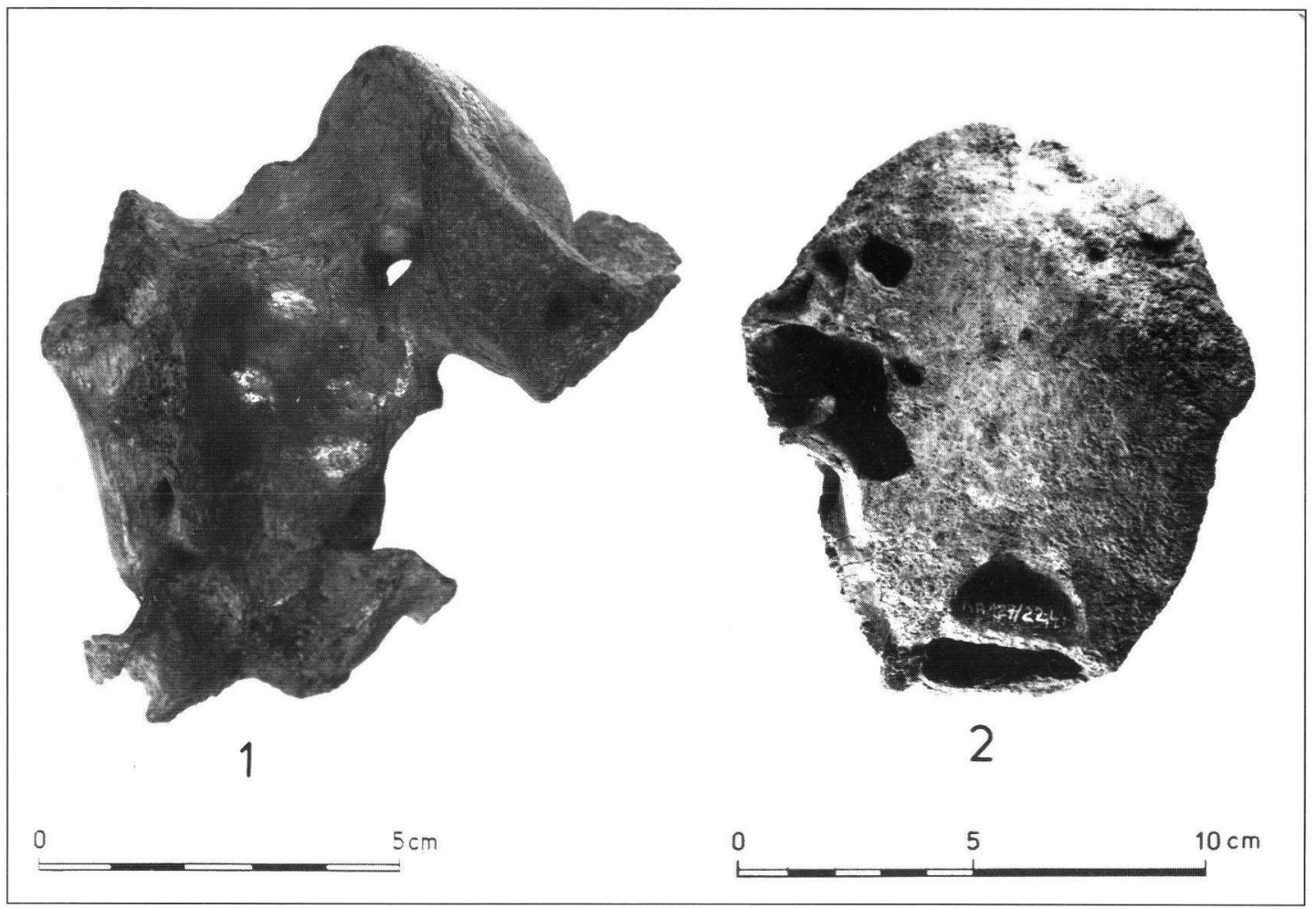

Abb. 11: Schädelfragmente in unterschiedlichen Abrasionsstadien. 1. Schädelfragment von Bos/Bison, 2. abradiertes Schädelfragment: Knochengeröll.

Fig. 11: Skull fragments showing differing abrasional stages. 1. Skull fragment from Bos Bison, 2) abraded skull fragment: bone pebble.

vertikal/horizontal zur Knochenstruktur verlaufender Bruchkanten gekennzeichnet, die auf starke Sedimentverdichtungen verweisen.

Durch Abrasion werden Knochen geglättet und $\mathrm{pO}^{-}$ liert. Für diese Oberflächenveränderung kann die Bewegung in steinigem, sandigem Sediment angenommen werden. Bei stark fragmentiertem Material kann eine solche Erosion auch zur Materialzerkleinerung führen. Verrollungsspuren an Knochen gelten gemeinhin als Indikator für den Zeitraum zwischen der Disartikulation des Knochens vom Skelett und der endgültigen Einsedimentierung (BEHRENSMEYER 1991). Unter Berücksichtigung dieses Aspektes können Knochen mit stark abradierten Oberflächen als ,ältere" Elemente und solche ohne Abrasionsmerkmale als ,jüngere“ Komponenten einer Faunengemeinschaft interpretiert werden. Wieder konnte durch die detaillierte Analyse der Befundsituation gezeigt werden, daß Abrasion an Knochen des Kärlicher Seeufers unabhängig vom einbettenden Sediment auftritt. Klimatisch bedingte Verwitterungsmerkmale könnten ebenfalls einen Hinweis auf den Zeitraum liefern, den Knochen vor ihrer Einbettung auf der Oberfläche gelegen haben. Detaillierte Analysen belegen auch hier das Nebeneinander verwitterter und unverwitterter Skelettelemente im archäologischen Befund.
Das Nebeneinander stark beanspruchter und unbeanspruchter (Abb. 11) Skelettelemente zeigt, daß sich die Knochen offenbar durch unterschiedliche „Lebensgeschichten“ auszeichnen, die als Reflektion einer allochthonen Grabgemeinschaft interpretiert werden können. Das charakteristische Merkmal allochthoner Thanatocoenosen ist der vorherige Transport oder die Verfrachtung von Leichen oder Leichenteilen vor der endgültigen Einbettung. Allochthone Thanatocoenosen setzen sich zumeist aus toten Wesen unterschiedlicher Lebensgemeinschaften zusammen (MüLler 1951). Gleiches ist auch für die Grabgemeinschaft des Kärlicher Seeufers zu postulieren. Abrasionsmerkmale, aber auch gleichgerichtet verlaufende Schrammen und Kratzer auf unabradierten Oberflächen verschiedener Knochen, aber auch die Anwesenheit von Knochengeröllen zeugen vom Zusammenwirken von Knochen und Sedimenten. Wahrscheinlich gelangte der Großteil der Skelettelemente durch Sedimenttransport zur Fundstelle. Um zu klären, ob es sich bei den überlieferten Skelettelementen um Reste hominider und/ oder tierischer Subsistenzstrategien handelt, sollen sich weitere Überlegungen anschließen.

An keinem der Kärlicher Skelettelemente können Spuren menschlicher Einflußnahme, in Form von 
Schnitt- oder Schlagspuren, beobachtet werden. Sollten Hominiden auf die gesamte oder auf einen Teil der Kärlich-Seeufer-Thanatocoenose eingewirkt haben, so kann dies nur aus indirekten Hinweisen, wie z. B. der Skeletteilpräsenz (BINFORD 1981, BuUMENSCHINE 1986, LYMAN 1992) oder der Alterszusammensetzung (StINER 1994), geschlossen werden. Die Untersuchung beider Aspekte wird aufgrund der rudimentären Überlieferung der Faunenreste stark erschwert.

So zeigte die Untersuchung der Skeletteilpräsenz (GAUdZInski 1995a), daß die selektive Überlieferung der Tierkarkassen offenbar nicht als das Ergebnis diagenetischer in situ-Zerstörungsprozesse interpretiert werden kann. Bei diagenetisch bedingter Knochenzersetzung werden in der Regel Elemente begünstigt, die sich durch eine hohe Knochendichte auszeichnen (z. B. Zähne, Metapodien, Hand- oder Fußwurzelknochen, vgl. BeitensmeYer 1975, LyMAN 1994). Gerade bei den Boviden läßt sich das Nebeneinander von Knochen mit hoher Dichte (z. B. Zähne, Metapodien) neben solchen geringer Dichte (vollständige Wirbel und Becken) beobachten (vgl. Kreutzer 1992). Eine solche qualitative und quantitative Selektion der Skelettelemente könnte wiederum die zuvor geäußerte Annahme von der allochthonen Thanatocoenose unterstreichen. Aussagen, inwiefern hier menschliche oder tierische Subsistenzstrategien reflektiert sind, können nicht getroffen werden.

Gleiches gilt für die Interpretation der Alterszusammensetzung, die lediglich für die Elefanten versucht wurde. Zur Interpretation der Alterszusammensetzung von Elefantenpopulationen wurde eine Einteilung der Lebenserwartung in 12 Jahre währende Phasen vorgeschlagen (HAYNES 1991). Die einzelnen Phasen entsprechen verschieden charakterisierten Abschnitten im Leben eines Elefanten wie z. B. dem Einsetzen der Geschlechtsreife (Beginn der Altersklasse 2), dem Beginn der Reproduktion (Beginn der Altersklasse 3) oder dem Höhepunkt der Reproduktivität (Beginn der Altersklasse 4). Eine solche Einteilung hat den Vorteil, daß die problematische jahrgenaue Alterszuweisung der Elefanten bei der Interpretation der Daten in den Hintergrund rückt. Das Altersprofil für die Elefanten vom Fundplatz Kärlich-Seeufer ist musterlos (vgl. Tab. 6) und kann daher auch nicht im Sinne menschlicher Verhaltensmuster interpretiert werden (vgl. dazu auch HaYNEs 1991: 217, Altersprofil Typ D).

Auf den Knochen vom Fundplatz Kärlich-Seeufer lassen sich zwar keine Spuren menschlicher Aktivitäten erkennen, biotische Veränderungen durch Carnivoren sind indes zahlreich belegt (GAUDZINSKI 1995a).

Zusammenfassend liefert die Kärlicher Thanatocoenose keinen Hinweis auf menschliche Einflußnah- me. Schnitt- und Schlagspuren fehlen und das Faunenensemble ist von einer selektiven Überlieferung gekennzeichnet. Die qualitative und quantitative Zusammensetzung der Faunenakkumulation läßt sich ebenfalls kaum interpretieren. Dagegen ist eine starke Modifikation der Thanatocoenose durch Carnivoren evident. Veränderungen auf den Knochenoberflächen, wie Abrasionsmerkmale und die Anwesenheit von Knochengeröllen, lassen ein intensives Transportgeschehen plausibel erscheinen.

\section{Die Holzreste}

Vom Fundplatz Kärlich-Seeufer konnten insgesamt ca. 12000 Holz- sowie zahlreiche Fruchtreste geborgen werden. Neben gut erhaltenen Stücken fand sich ebenso stark zersetztes, z. T. verkieseltes Holz. Baumstämme und Asthölzer sind in unterschiedlicher Ausprägung überliefert. Stubben fehlen vollständig, Wurzelhölzer sind dagegen zahlreich belegt. Der Großteil der Holzreste ist durch Sedimentdruck verändert.

Die Baumstämme sind abgeflacht und zeigen einen spitzovalen Querschnitt. Kleinere Asthölzer sind weniger von einer Veränderung durch Druck betroffen. Einige der Hölzer sind durch Insektenbefall gekennzeichnet. Soweit Verfasserinkenntnis reicht, handelt es sich dabei am ehesten um Fraßgänge des Prachtkäfers Buprestis sp. (vgl. Kuinger \& v. Koenigswald 1984, KLINGER 1988).

Der Großteil der Hölzer fällt in die Größenklassse unter $10 \mathrm{~cm}$, es konnten jedoch ebenso Baumstämme mit einer Länge von 6,50 geborgen werden. Die holzanatomischen Bestimmungen wurden von $\mathrm{F}$. BitTMAnN durchgeführt. Unter den Hölzern konnten folgende Taxa wie nach Tab. 7 bestimmt werden.

Reste von Tannen dominieren das Holzspektrum mit nahezu 60\%, gefolgt von Resten der Eiche. Die Akkumulation setzt sich zum großen Teil, unabhängig von der Holzart, aus Fragmenten mit einer Größe unter $10 \mathrm{~cm}$ zusammen. Die gleichartige Fragmentation der Holzarten legt nahe, daß die Gesamtheit der Hölzer gleichartigen taphonomischen Prozessen unterworfen war. Mit Ausnahme der Tanne geht, mit der Abnahme in der Fundhäufigkeit der einzelnen Holztypen, eine Abnahme im Längen-, Breiten- und Dickenverhältnis einher.

Wie dendrochronologische Untersuchungsergebnisse durch $\mathrm{H}$. H. Leuschner plausibel erscheinen lassen, repräsentieren die Holzreste insgesamt nur wenige Individuen. Die Ergebnisse zeigen darüber hinaus, daß die Eichen offenbar an unterschiedlichen Standorten wuchsen. Die nur geringen Ringbreiten der Eichenhölzer verweisen auf schlechte bis extrem schlechte klimatische oder standörtliche Bedingungen. Die Ringbreiten anderer Proben waren hingegen denen rezenter Eichen von Nor- 
Tab. 7: Häufigkeit unterschiedlicher Holzarten vom Fundplatz Kärlich-Seeufer.

Taxaceae

Taxus Holztyxp

(Eibe)

\section{Pinaceae}

Abies Holztyp

(Tanne)

Picea/Larix Holztyp

(Fichte/Lärche)

Pinus Holztyp

(Kiefer)

\section{Salicaceae}

Salicaceae Holztyp, insges.

Populus Holztyp

(Pappel)

Salix Holztyp

(Weide)

\section{Betulaceae}

Betula Holztyp

(Birke)

Carpinus Holztyp

(Hainbuche)

Corylus

(Haselstrauch)

\section{Fagaceae}

Quercus Holztyp

(Eiche)

\section{Ulmaceae}

Ulmus Holztyp

(Ulme)

Celtis/Zelkova Holztyp

(Zürgelbaum)

\section{Rosaceae}

Pomoideae Holztyp

(Kernobst)

Prunoideae Holztyp

(Steinobst)

\section{Aceraceae}

Acer Holztyp

(Ahorn)

\section{Cornaceae}

Cornus Holztyp

(Kornelkirsche/Hartriegel)

\section{Oleaceae}

Fraxinus Holztyp

(Esche)

\section{Caprifoliaceae}

Lonicera

(Geißblatt)

Sambucaceae

Sambucus

(Holunder)

indet.

$$
0,5 \% \quad(n=37)
$$

$\begin{array}{cr}58,7 & (n=4300) \\ 1,0 \% & (n=76) \\ 0,04 \% & (n=3)\end{array}$

$3,1 \%$

$(\mathrm{n}=154)$

$$
0,7 \% \quad(n=49)
$$

$4,2 \% \quad(n=299)$

$1,4 \% \quad(n=100)$

$0,04 \% \quad(n=3)$

$11,5 \% \quad(n=844)$

$0,2 \% \quad(n=17)$

$0,08 \% \quad(n=6)$

$1,5 \% \quad(n=112)$

$0,05 \% \quad(n=4)$

$0,2 \% \quad(n=17)$

$0,2 \% \quad(n=13)$

$0,8 \% \quad(n=62)$

$0,02 \% \quad(n=2)$

$0,05 \% \quad(n=4)$

$13,6 \% \quad(n=1000)$

$(\mathrm{n}$ gesamt=7331) malstandorten vergleichbar (GAUDzINSKI 1995a). Fossile Vergesellschaftungen von Pflanzen bilden sich nur, wenn die Reste sehr schnell sedimentiert werden. Sedimentbewegungen spielen hier immer eine Rolle und deshalb sind Plätze, an denen sich solche Akkumulationen bilden, immer dynamisch (SPICER 1989). Wie auch am Kärlicher Seeufer, so sind Holzreste in klastischen Sedimenten meist komprimiert überliefert (GreENwoOd 1991). Mit der Ausnahme von Pflanzenresten in Torfen müssen fossile Pflanzengesellschaften fast ausschließlich als allochthon betrachtet werden.

Auch die Holzakkumulation am Kärlicher Seeufer dürfte zusammen mit Sedimenteintrag entstanden sein. Wahrscheinlich wurden Hölzer durch Schlammschübe transportiert und gleichzeitig sedimentiert. Es muß offen bleiben, in welchem Zustand die Hölzer umgelagert wurden. Das Fehlen von Stubben spricht zunächst für die Fragmentation der Hölzer vor der Umlagerung. Unterstrichen werden könnte dies durch die Anwesenheit der Bohrkäfergänge, da Bohrkäfer fast ausschließlich an abgestorbenes Holz gebunden sind. Die Ergebnisse der dendrochronologischen Untersuchung legen, mit dem Nachweis von Bäumen von extrem schlechten Standortbedingungen (wie z. B. sumpfigem Gelände), nahe, daß die Holzakkumulation durch autochthone Elemente bereichert worden sein könnte. Hinweise auf die Nutzung der Hölzer als Rohmaterial zur Geräteherstellung durch Hominiden liegen nicht vor.

\section{Die räumliche Verteilung}

Abschließend soll die räumliche Verteilung aller Fundgattungen im archäologischen Befund beispielhaft betrachtet werden. Es wurden Horizontalkartierungen vorgenommen. Vor allem aber dienten Profilprojektionen zur Klärung des Befundes. Da das fundführende Sediment stark aus zwei Richtungen einfällt, wurden die Projektionen quadratmeterreihenweise, sowohl entlang der $\mathrm{x}$ - als auch entlang der y-Achse der Grabungsfläche erstellt. Auf diesem Weg konnte der gesamte Befund „in Scheiben“ betrachtet werden. Trotzdem wurden weiterreichende Aussagen zu Fundzusammenhängen aufgrund der teilweise sehr niedrigen Funddichte erschwert.

Der Befund ist in der Horizontalen durch das Nebeneinander von Funden aller Gattungen gekennzeichnet (Abb. 12, 13). Hölzer treten ab der Quadratmeterreihe $\mathrm{x} / 16$ auf (Abb. 12) und zeigen eine Größensortierung im Befund. Im tiefsten Bereich der Grabungsfläche liegen Hölzer des kleinsten Fragmentationsgrades. Hangaufwärts nimmt die Größe der Hölzer kontinuierlich zu. Es ist anzunehmen, daß der Holzsaum den Bereich der Grabungsfläche charakterisiert, der über einen längeren Zeit- 


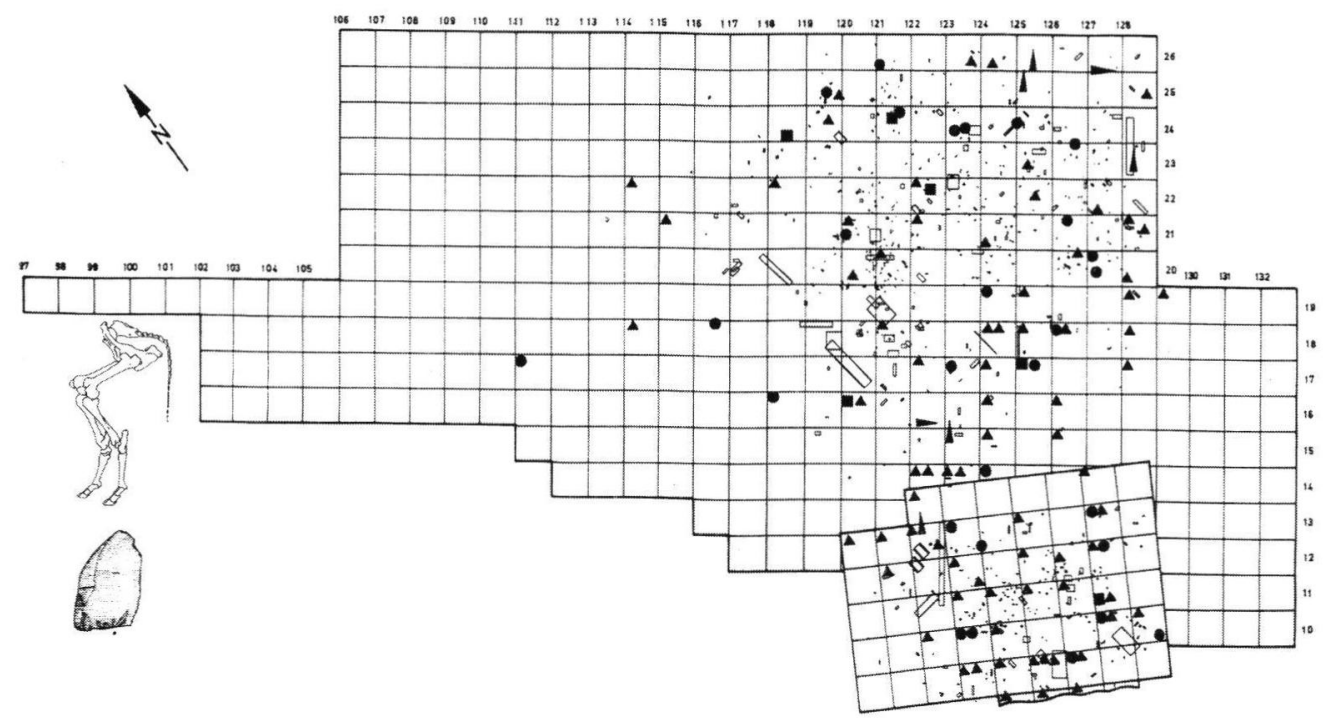

Abb. 12: Horizontale Verteilung von Artefakten und Faunenresten über die Grabungsfläche der Fundstelle Kärlich-Seeufer. Die Faunenreste sind schematisiert, entsprechend ihrer natürlichen Form angegeben. • retuschierte Abschläge, Abschlaggeräte $\boldsymbol{\Delta}$ unretuschierte Abschläge, $\mathbf{D}$ Kerne, $>$ bifaziell bearbeitete Geräte, $>$ retuschierte "Stücke“.

Fig. 12: Horizontal distribution of artefacts and faunal remains over the excavated area of the Kärlich-Seeufer site. The faunal remains are given schematically, according to their natural shape. - retouched flake, tools, $\boldsymbol{\Delta}$ unretouched flakes, $\mathbf{m}$ cores, $>$ biacial worked tools, retouched "pieces".

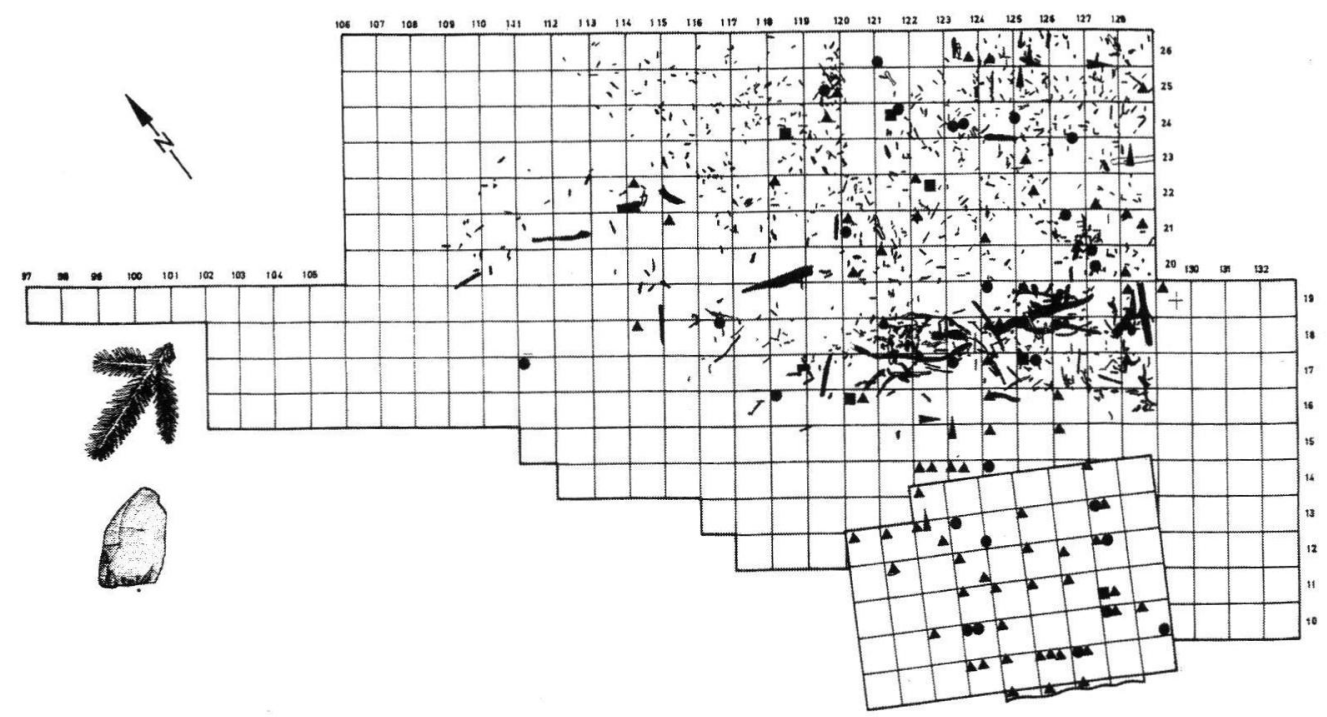

Abb. 13: Horizontale Verteilung der Tannenreste mit einer Länge größer als $10 \mathrm{~cm}$ und der Artefakte über die Grabungsfläche der Fundstelle Kärlich-Seeufer. - retuschierte Abschläge, Abschlaggeräte, $\boldsymbol{\Delta}$ unretuschierte Abschläge, $\mathbf{\square}$ Kerne, > bifaziell bearbeitete Geräte, > retuschierte "Stücke“.

Fig. 13: Horizontal distribution of remains of fir longer than $10 \mathrm{~cm}$ and artefacts over the excavated area of the Kärlich-Seeufer site. - retouched flakes, $\boldsymbol{\Delta}$ tools unretouched flakes, - cores, $>$ bifacial worked tools, $>$ retouched "pieces“.

raum wasserbestanden war (Abb. 12). Steinartefakte und Faunenreste streuen in der Horizontalen nach keinem erkennbaren Muster über die Grabungsfläche
(Abb. 12). Insgesamt dünnt die Fundschicht ab der Quadratmeterreihe 119/y aus. Das Ausdünnen der Funde steht mit dem Ausdünnen des 

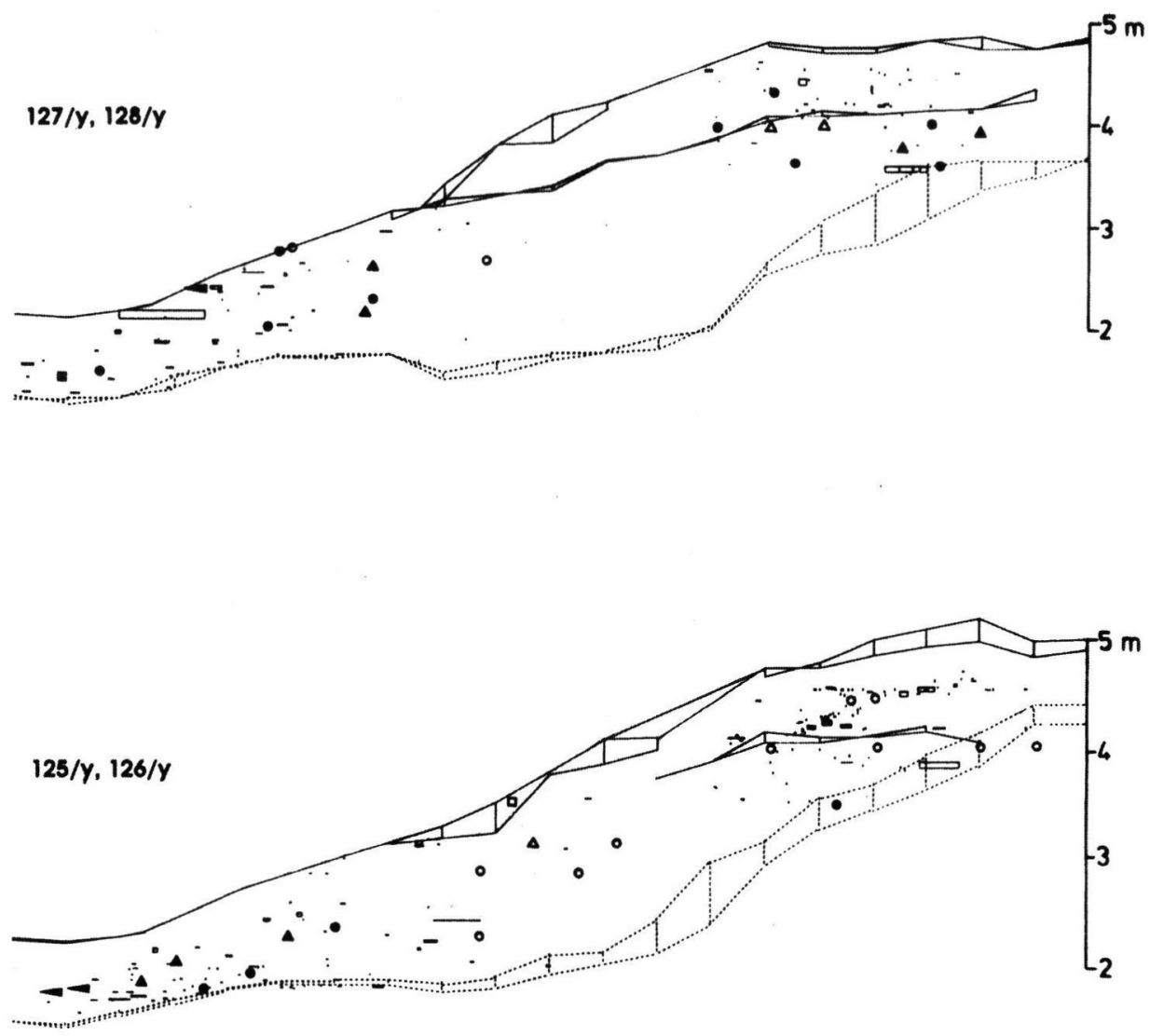

\begin{tabular}{lllllllllll}
\hline 26 & 24 & 22 & $20^{\prime}$ & 18 & 16 & 14 & 12 & $10^{\prime}$ & 08
\end{tabular}

Abb. 14: Vertikalstreuung von Faunenresten und Artefakten innerhalb der Quadratmeterreihen 127/y bis 125/y (vgl. Abb. 13). Auf der Abszisse sind die Quadratmeterbezeichnungen entlang der y-Achse der Grabungsfläche abgetragen. Auf der Ordinate ist die Höhe abgetragen. Die Faunenreste sind schematisiert, entsprechend ihrer natürlichen Form angegeben. - unretuschierte Abschläge, $\boldsymbol{\Delta}$ retuschierte Abschläge, Abschlaggeräte, $\mathbf{\square}$ Kerne, bifaziell bearbeitete Geräte, $<$ retuschierte „Stücke“. Die unausgefüllten Symbole bezeichnen Sammelfunde, deren Höhe in der Vertikalen um bis zu $10 \mathrm{~cm}$ höher liegen kann.

Fig. 14: Vertical distribution of faunal remains and artefacts in square-meter rows $127 / \mathrm{y}-125 / \mathrm{y}$ (compare fig. 13). Square meters on the $y$-axis of the excavated area are given on the abscissa. Height is given on the ordinate. The faunal remains are given schematically, according to their natural shape. - unretouched flakes, $\boldsymbol{\Delta}$ retouched flakes and tools, $\mathbf{\square}$ cores, bifacially workes tools, $\boldsymbol{<}$ retouched "pieces". The unfilled symbols stand for collected finds and their vertical height can be up to $10 \mathrm{~cm}$ higher.

fundführenden Sediments in Zusammenhang (Abb. $4,12,13)$.

In der Vertikalen verteilen sich die Funde aller Gattungen von der Ober- bis zur Unterkante des fundführenden Sedimentpaketes (Abb. 14, 15). Innerhalb eines Quadratmeters können Funde durch über einen Meter fundleeres Sediment getrennt werden (vgl. z. B. Abb. 14). Eine interpretierbare Regelhaftigkeit wird aus dieser Vertikalverteilung allerdings nicht ersichtlich. Die mächtigste Vertikaldistanz zwischen Knochen beträgt innerhalb eines Quadratmeters $211 \mathrm{~cm}$. Die Steinartefakte streuen bis zu $150 \mathrm{~cm}$ und die mächtigste Vertikalstreuung der Hölzer in einem Quadratmeter beträgt $130 \mathrm{~cm}$. Die größenund gewichtsabhängige Sortierung, die für die Hölzer in der Horizontalen gefaßt werden konnte, zeigt sich auch in der Vertikalen.

Es stellt sich zunächst die Frage, ob diese Vertikal- 

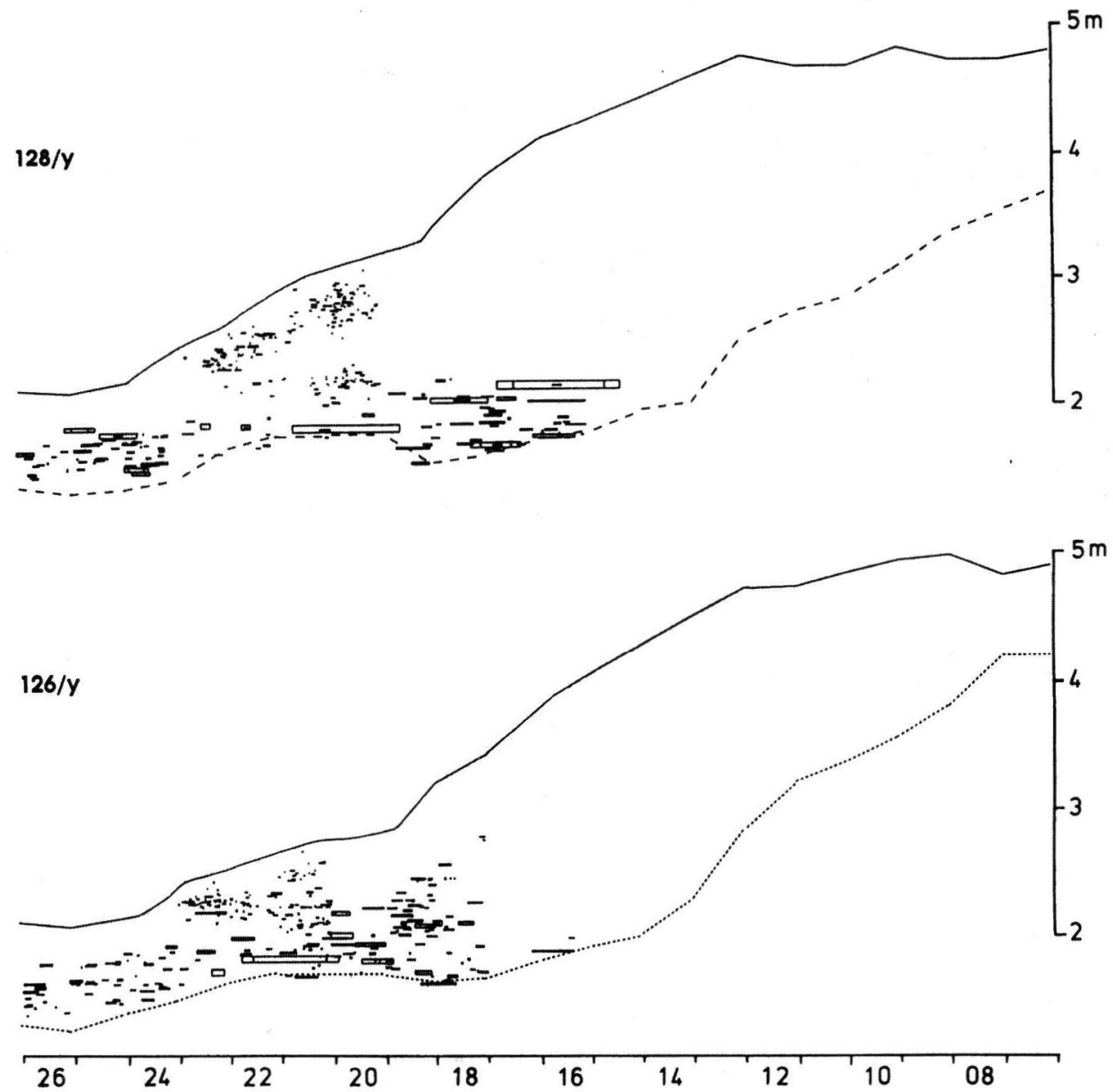

Abb. 15: Vertikalstreuung der Hölzer innerhalb der Quadratmeterreihen 128/y und 126/y (vgl. Abb. 13). Auf der Abszisse sind die Quadratmeter entlang der y-Achse der Grabungsfläche abgetragen. Auf der Ordinate ist die Höhe abgetragen. Die Hölzer sind schematisiert, entsprechend ihrer natürlichen Form angegeben.

Fig. 15: Vertical distribution of wood in square-meter rows $128 / y$ and $126 / y$ (compare fig. 13). Square meters on the $y$-axis of the excavated area are given on the abscissa. Height is given on the ordinate. The wooden remains are given schematically, according to their natural shape.

verteilung das Ergebnis kontinuierlicher Sedimentationsprozesse ist oder ob alle Funde ursprünglich einen Horizont bildeten, der heute auseinandergezogen und nicht mehr erkennbar ist. Für postdepositionale Vertikalbewegungen von archäologischen Funden können eine Reihe von physioenergetischen und/oder bioenergetischen Prozessen verantwortlich sein (vgl. WoOD \& JoHnson 1978). Die Dynamiken, nach denen sich die Funde im Sediment bewegen, werden heute noch nicht verstanden. Zunächst war eine gewichtsabhängige Sortierung postuliert worden (VILLA \& CourTin 1983). Andere Arbeiten zeigen aber, daß eine solche Selektion nur dann beobachtet werden kann, wenn die Vertikaldistanz der Funde nicht mehr als $30 \mathrm{~cm}$ beträgt (vgl. GIFFORD et al. 1985). Vertikalbewegungen von Funden können ohne sichtbare sedimentäre Störungen auftreten (VILLA 1982) und sind abhängig vom sedimentologischen Kontext (vgl. STOCKTON 1973, VILLA 1982, Villa \& COURTIN 1982, Hofman 1986). Wenn Fundschichten in der Vertikalen auseinandergezogen sind, so bleiben sie dennoch häufig als Horizont erkennbar, ohne daß jedoch einzelne Phasen unterschieden werden können.

Mit den Profilprojektionen, die für den Kärlich-Seeufer Befund erstellt wurden, sollte ein solcher Hori- 
zont sichtbar gemacht werden. Eine solche Horizontierung tritt im Kärlicher Befund jedoch nicht auf. Zusammen mit der größen- und gewichtsabhängigen Sortierung der Hölzer legt dieser Aspekt nahe, daß die Einlagerung der Holzreste offenbar das Ergebnis von Umlagerungsprozessen ist. Die qualitative und quantitative Analyse des Kiesanteils im fundführenden Sedimentpaket unterstreicht dies (KulEMEYER 1988). KuLEMEYERS „Körnungsanalyse“ belegte die Abnahme größerer Steine und die Zunahme kleinerer Steine zur Basis des fundführenden Sedimentpaketes. Hölzer, die unmittelbar an den analysierten Grabungsbereich angrenzen, selektieren sich in gleicher Weise. Diese Beobachtung unterstreicht die Hypothese vom Holz als natürlichem Sedimentbestandteil. Die räumliche Verteilung für alle Fundgattungen mehr oder weniger gleich. Insofern ereilte zumindest Teile des lithischen Materials und der Fauna offenbar gleiches Schicksal wie die Hölzer. Der Nachweis von Abrasionserscheinungen auf den Oberflächen einiger Steingeräte, vor allem aber der Knochen, können als weitere Anzeichen für hydraulische Umarbeitungserscheinungen bewertet werden.

\section{Fazit}

Die Rolle von Hominiden bei der Genese der Fundstelle Kärlich-Seeufer darzulegen ist überaus schwierig. Direkte Begehungen durch Hominiden könnten am Ort stattgefunden haben. Steingeräte, die sich durch einen extrem frischen Erhaltungszustand auszeichnen, lassen dies sogar plausibel erscheinen. Erosion und Umlagerung haben indes in einem Maß eingewirkt, das die Überlieferung solcher potentiellen Befunde unmöglich macht. Die Annahme eines in unmittelbarer Umgebung der Fundstelle gelegenen Platzes, dessen Reste zur heutigen Fundstelle umgelagert wurden, würde die bereits beschriebene Gleichartigkeit des lithischen Ensembles sowie die Anwesenheit der Zusammenpassungen erklären. Von der Bereicherung des lithischen Inventars durch Artefakte, die möglicherweise aus anderen Bereichen der Tongrube umgelagert worden sein könnten, wurde ebenfalls berichtet. Knochengerölle legen beredtes Zeugnis davon ab, daß außer den Artefakten auch Faunenreste durch Transport an den Platz gelangt sein könnten. Gleiches dürfte auch für die Holzreste gelten. Die Depression, in der die fundführenden Sedimente abgelagert wurden, fungierte wahrscheinlich als Sedimentfalle, in die Ablagerungen und Fundmaterial während eines Interglazials eingetragen wurden.

Die vorgelegte Interpretation der Fundstelle KärlichSeeufer unterscheidet sich von der vorangegangener Jahre, die viele der Muster beinhaltete, die die Sichtweise zum Altpaläolithikum über lange Zeit geprägt haben und noch heute prägen. Zu nennen sind hier einige Schlagworte wie: Elefantenjagdplatz, hölzerne Gerätschaften wie z. B. Lanzen, Geräte wie Knochenmeißel, Konstruktionen aus Holz (BOsINSKI et al. 1980, Bosinski 1983, Kulemeyer 1988, Kröger et al. 1992). Die kritische Betrachtung aller Fundgattungen zeigt jedoch, daß keines dieser Elemente den Kärlich-Seeufer-Befund charakterisiert.

Nicht nur am Kärlicher Seeufer führte eine umfassende kritische Betrachtung zur Revision bis dahin veröffentlichter Ergebnisse. So wurden auch die Fundstellen Torralba und Ambrona (Spanien) über lange Zeit als Nachweis für die Großwildjagd (speziell auf Elephas antiquus) im Mittelpleistozän betrachtet (FreEman 1975). Nachdem sich inzwischen eine Reihe von Forschern mit dem Fundmaterial beider Plätze beschäftigt hat, herrscht allgemeiner Konsens darüber, daß der archäologische Nachweis, ähnlich wie am Kärlicher Seeufer, zu gestört ist, um die Rolle des Menschen plausibel zu evaluieren (Binford 1987, Santonja \& Villa 1990, Villa 1990, HAYNES 1991). Auch an anderen mittelpleistozänen Plätzen, deren faunistischer Nachweis durch ein hohes zahlenmäßiges Auftreten von Elephas antiquus gekennzeichnet ist, ist der Anteil des Menschen sowohl am Tod der Elefanten als auch für die Genese der Fundstellen schwierig zu ermitteln. Zu nennen sind hier z. B. Rebibbia (Italien) (ANzideI \& RufFo 1985), La Polledrara (Italien) (ANZideI et al. 1989, ANZIDEI \& ARNOLDUS-HuYZENIDVELT 1992) oder auch Fonatana Ranuccio (Italien) (Bidduttu \& SEgRe 1982, Bidduttu et al. 1979, Segre et al. 1987). Die archäologischen Nachweise scheinen in der Hauptsache durch fluviatilen Im- und Export gekennzeichnet, reflektieren lange taphonomische Geschichten und belegen, durch das lithische Material, verschiedenartige Begehungen durch Hominiden in der Umgebung dieser Plätze (GAudzinski 1995a). Insofern steht der Nachweis vom Fundplatz Kärlich-Seeufer durchaus im Kontext anderer mittelpleistozäner Plätze, die sich durch vergleichbare archäologische Nachweise auszeichnen.

Die mittelpleistozäne Fundstelle Kärlich-Seeufer liefert wichtigte Ergebnisse für die Rekonstruktion ökologischer Bedingungen während einer interglazialen Phase und kann gleichzeitig als gutes Beispiel für die Komplexität unserer geologischen Nachweise herangezogen werden, bei denen Hominiden nur eine Variable sind.

\section{Danksagung}

Für Anregungen und Diskussionen zu diesem Beitrag möchte ich mich herzlich bei Dr. M. Street (Neuwied) und Dr. F. Bittmann (Göttingen) bedanken. Letzterer sei darüber hinaus für die Bereitstellung des bisher unpublizierten Pollenprofils Kärlich E (Abb. 3) herzlich bedankt. 


\section{Schriftenverzeichnis}

Anzidei, A. P. \& Ruffo, M. (1985): The Pleistocene deposit of Rebibbia - Casal de'Pazii (Rome - Italy). - In: MaLoNE, C. \& STODDART, S. [Hrsg.]: Papers in Italian Archaeology IV. The human landscape. - S. 69-85; BAR International Series 243: Oxford.

AnZidei, A.P., Angelelli, A., ARnoldus-Huyzendveld, A., Caloi, L., Palombo, M. R. \& Segre, A. G. (1989): Le gisement pléistocène de La Polledrara Di Cecanibbio (Rome, Italie). - L'Anthropologie 93: 749-782; Paris. - \& Arnoldus-Huyzendveld, A. (1992): The Lower Palaeolithic site of La Polledrara di Cecanibbio (Rome, Italy). - In: Herring, E., Whitehouse, R. \& Wilkins, J. [Hrsg.]: New developments in Italian Archaeology. S. 141-153; London (Accordia Research Centre).

Ashton, N. M., Cook, J., Lewis, S. G. \& Rose, J. (1992): High Lodge. Excavations by G. de Sieveking 1962-1968 and J. Cook 1988. - 192 S., London (The British Museum Press).

Behrensmeyer, A. K. (1975): The taphonomy and palaeoecology of Plio-Pleistocene vertebrate assemblages east of Lake Rudolf, Kenya. - Bulletin Museum of Comparative Zoology 146: 473-578; Cambridge, Mass.

- (1978): Taphonomic and ecological information from bone-weathering. - Paleobiology 4: 150-162; Chicago.

- (1991): Terrestrial vertebrate accumulations. In: AtciSON, P. A. \& Briggs D.E.G. [Hrsg.]: Taphonomy. Releasing the data locked in the fossil record. - S. 291-335; New York (Plenum Press)

Biddittu, I.; Cassoli, P. F.; Radicati di Brozolo, F.; Segre, A. G.; Segre Naldini, E. \& Vili.a, I. (1979): Anagni, a KAr dated Lower and Middle Pleistocene site, Central Italy: preliminary report. - Quaternaria 21: 53-71; Roma.

Biddittu, I. \& Segre, A. G. (1982): Pleistocene medio-inferiore con industria arcaica su ciottolo nel Bacino di Anagni (Lazio). - Estratto dagli atti della XXIII riunione scientifica dell'Istituto Italiano di Preistoria e Protostoria, Firenze, 7-9 Maggio 1980. - S. 567-576; Firenze.

Binford, L. R. 1981): Bones. Ancient men and modern myths. - 320 S., New York, London (Academic Press). - (1987): Were there elephant hunters at Torralba? - In: NiteCKI, M. H. \& NITECKI, D. V. [Hrsg.]: The evolution of human hunting. S. 47-106; New York, London (Plenum Press).

Brttmann, F. (1991): Vegetationsgeschichtliche Untersuchungen an mittel- und jungpleistozänen Ablagerungen des Neuwieder Beckens (Mittelrhein). - Unveröffentlichte Dissertation, 107 S.; Göttingen.

- (1992): The Kärlich Interglacial, Middle Rhine region, Germany: vegetation history and stratigraphic position. - Vegetation History and Archaeobotany 1: 243258; Berlin, Heidelberg.

Buumenschine, R. J. (1986): Early hominid scavenging opportunities, implications of carcass availability in the Serengeti and Ngorongoro ecosystems. - BAR International Series 283, 163 S.; Oxford.

Boenigk, W. (1978): Die flußgeschichtliche Entwicklung der Niederrheinischen Bucht im Jungtertiär und Altquartär. - Eiszeitalter u. Gegenwart 28: 1-9; Hannover. - ; Heye, D.; Schirmer, W. \& Brunnacker, K. (1974): Paläomagnetische Messungen an vielgliedrigen Quartär-Profilen (Kärlich Mittelrhein und Bad Soden i. Taunus). - Mainzer Naturwissenschaftliches Archiv 12: 159-168; Mainz.
Bogatrd, C., v. d., Bogatrd, P., v d. \& Schmincke, H.-U. (1989): Quartärgeologisch-Tephrostratigraphische Neuaufnahme und Interpretation des Pleistozänprofils Kärlich. - Eiszeitalter u. Gegenwart 39: 62-86; Hannover.

- \& Schmincke, H.-U. (1990): Die Entwicklungsgeschichte des Mittelrheinraumes und die Eruptionsgeschichte des Osteifel-Vulkanfeldes. - In: SCHIRMER, W. [Hrsg.]: Rheingeschichte zwischen Mosel und Maas. S. 166-190; DEUQUA Führer 1; Hannover.

Bosinski, G.; Brunnacker, K.; Lanser, K. P.; Stephan, S.; URBAN, B. \& WÜrGES, K. (1980): Altpaläolithische Funde von Kärlich, Kreis Mayen-Koblenz (Neuwieder Becken). - Archäologisches Korrespondenzblatt 10: 295-314; Mainz.

-(1983): Die Ausgrabungen in Kärlich/Neuwieder Becken. - Beil. Jahresber. Gerda-Henkel-Stiftung 1982 9-20; Düsseldorf

Brunnacker, K.; Streit, R. \& Schirmer, W. (1969): Der Aufbau des Quartär-Profils von Kärlich/Neuwieder Becken (Mittelrhein. - Mainer Naturwissenschaftliches Archiv 8: 102-133; Mainz.

- ; Heller, F. \& Lozek, V. (1971): Beiträge zur Stratigraphie des Quartär-Profils von Kärlich am Mittelrhein. Mainzer Naturwissenschaftliches Archiv 10: 77-100; Mainz.

Cl.ARK, J. D. (1958): The natural fracture of pebbles from the Batoka Gorge, Northern Rhodesia, and its bearings on the Kafuan Industries of Africa. Proceedings of the Prehistoric Society 24: 64-77; London.

Delpech, F. \& Heintz, E. (1976): Les Artiodactyles: Cervidés. - In: De Lumley, H. [Hrsg.]: La Préhistoire Francaise, Tome 1.1. - S. 397-404; Paris (Edition du CNRS).

Driesch, v. d. A. (1976): A guide to the measurement of animal bones from archaeological sites. - Peabody Museum Bulletin 1; Cambridge, Mass.

Fatti, L. G.; Smuts, G. L.; Starfield, A. M. \& Spurdle, A. A. (1980): Age determination in the African elephants. Journal of Mammalogy 61: 547-551.

FLoss, H. (1994): Rohmaterialversorgung im Paläolithikum des Mittelrheingebietes. - Monographien des RömischGermanischen Zentralmuseums Mainz 21; Bonn (Habelt).

Freeman, L. G. (1975): Acheulean sites and stratigraphy in Iberia and the Maghreb. - In: Butzer, K. W. \& IsAAC, G. L.. [Hrsg.]: After the Australopithecines. Stratigraphy, ecology, and culture change in the Middle Pleistocene. - S. 661-744; The Hague, Paris (Mouton Press).

GAUDZINSKI, S. (1994): Neue Untersuchungsergebnisse vom altpaläolithischen Fundplatz Kärlich-Seeufer. - Ethnographisch-Archäologische Zeitschrift 35: 10-18; Berlin. - (1995a): Kärlich-Seeufer. Untersuchungen zu einer altpaläolithischen Fundstelle im Neuwieder Becken (Rheinland/Deutschland). - Monographien des Römisch Germanischen Zentralmuseums Mainz; Bonn (Habelt). (Im Druck)

- (1995b): The Lower Palaeolithic site Kärlich-Seeufer In: Bosinski, G.; Sreet, M. \& BaAles, M. [Hrsg.]: The Palaeolithic and Mesolithic of the Rhineland. - S. 887-890; 14. Inqua-Congress, Quaternary field Trips in Central Europe 15, München (Pfeil).

- ; Bittmann, F.; Boenigk, W.; Frechen, M. \& v. Kolfschoten, T. (1995): The Middle Pleistocene open-air site Kärlich-Seeufer (Central Rhineland, Germany). Quaternary Research; New York. (Im Druck)

Gifford, D. P.; Damrosch, D. B.; Damrosch, D. R.; Pryor, J. \& Thunen, R. L. (1985): The third dimension in site structure: an experiment in trampling and vertical dis- 
persal. - American Antiquity 50: 803-818; Menasha. GREENWOOD, D. R. (1991): The taphonomy of plant macro fossils. - In: Donovan, S. K. [Hrsg.]: The processes of fossilization. - S. 141-169; London (Belhaven Press).

GuentHER, E. W. (1978): Die Elefantenmolaren aus den Travertinen von Burgtonna in Thüringen. - Quartärpaläontologie 3: 139-150; Berlin.

- (1989): Die Gebisse der Waldelefanten von Bilzingsleben. - Ethnographisch-Archäologische Zeitschrift 30: 416-450; Berlin.

Hahn, J.; Kind, C.-J. \& Steppan, K. (1993): Mesolithische Rentier-Jäger in Südwestdeutschland. Der mittelsteinzeitliche Freilandfundplatz Rottenburg „Siebenlinden I" (Vorbericht). - Fundberichte aus Baden-Württemberg 18: 29-52; Stuttgart.

HanKs, J. (1969): Growth in weight of the female African elephant in Zambia. - East African Wildlife Journal 7: 7-10.

Haynes, G. (1985): Age profiles in elephant and mammoth bone assemblages. - Quaternary Research 24: 333-345; New York.

-(1991): Mammoths, mastodonts and elephants. Biology, behavior, and the fossil record. - 412 S., Cambridge (Cambridge University Press).

Hofman, J. L. (1986): Vertical movements in alluvial and stratified deposits. - Current Anthropology 27: 163-171; Chicago.

Kuinger, R. \& Koenigswald, W. v. (1984): Insektenfraßspuren in interglazialen Hölzern aus den Sanden und Kiesen der nördlichen Oberrheinebene. - Eiszeitalter u. Gegenwart 34: 131-153; Hannover.

KLINGER, R. (1988): Insektenfunde in jungpleistozänen Hölzern der nördlichen Oberrheinebene. - In: KoENIGSWALD, W. v. [Hrsg.]: Zur Paläoklimatologie des letzten Interglazials im Nordteil der Oberrheinebene. - S. 173191; Paläoklimaforschung $\mathbf{4}$; Stuttgart-New York (G. Fischer).

Kolfschoten, T. v. (1990): The Evolution of the Mammal Fauna in the Netherlands and the Middle Rhine Area (Western Germany) during the Late Middle Pleistocene. - Mededelingen Rijks Geologische Dienst 43: 1-69; Haarlem.

- \& Turner, E. (1995): Early Middle Pleistocene mammalian faunas from Kärlich and Miesenheim I and their biostratigraphical implications. - Subdep. of Quaternary Reseach, Cromerian Symposium Vol.; New York (im Druck)

Kreutzer, L. A. (1992): Bison and Deer bone mineral densities: Comparisons and implications for the Interpretation of archaeological faunas. Journal of Archaeological Science 19: 271-294; London.

Kröger, K.; Bogaard, P. v. D.; Bittmann, F. \& Turner, E. (1991): Der Fundplatz Kärlich-Seeufer. Neue Untersuchungen zum Altpaläolithikum im Rheinland. - Jahrbuch des Römisch-Germanischen Zentralmuseums Mainz 35, 111-135; Bonn.

Kroll, W. (1991): Der Waldelefant von Crumstadt. Ein Beitrag zur Osteologie des Waldelefanten, Elephas (Palaeolodoxon) antiquus. - Unveröffentlichte Dissertation, 104 S.; München.

KULEMEYER, J. (1988): Die alt- und mittelpaläolithischen Funde von Kärlich. - Unveröffentlichte Dissertation, 199 S., Köln.

KuRTÉN, B. (1968): Pleistocene mammals of Europe. - London (Clowes and Sons).

Laws, R. M. (1966): Age criteria for the African elephant Lo- xodonta a. africana. - East African Wildlife Journal 4: 1-37.

Lippolt, H. J.; Fuhrmann, U. \& Hradetzky, H. (1986): $40 \mathrm{AR} / 39 \mathrm{AR}$ age determinations on sanidines of the Eifel Volcanic Field (FG'RG): constrains on age and duration of a Middle Pleistocene cold period. - Chemical Geology 59: 187-204; Amsterdam.

Lyman, R. L. (1992): Anatomical considerations of utility curves in zooarchaeology. - Journal of Archaeological Science 19: 7-22; London.

- (1994): Vertebrate Taphonomy. - Cambridge (Cambridge University Press).

Maglio, V. J. (1973): Origin and evolution of the Elephantidae. - Transactions of the American Philosophical Society, New Series, Vol. 63,3; Philadelphia.

Mortelmans, G. (1947): Une cause d'erreur en préhistoire: la taille glaciaire. - Bulletin de la Société Royale Belge d'Anthropologie et Préhistoire LVIII: 60-71.

Müller, A. H. (1951): Grundlagen der Biostratonomie. - Abhandlungen der deutschen Akademie der Wissenschaften zu Berlin 3: 1-147; Berlin.

Müller, H. (1965): Eine pollenanalytische Neubearbeitung des Interglazial-Profils von Bilshausen (Unter-Eichsfeld). - Geologisches Jahrbuch 83: 327-352; Hannover. - (1992): Climate changes during and at the end of the interglacials of the Cromerian Complex. - In: KukL.A, G. J. \& WeNT, E. [Hrsg.]: Start of a Glacial. - S. 51-69; NATO ASI Series 13; Berlin, Heidelberg (Springer).

RAZI RAD, M. (1976): Schwermineraluntersuchungen zur Quartär-Stratigraphie am Mittelrhein. - Sonderveröffentlichungen des Geologischen Instituts der Universität zu Köln 28, 164 S.; Köln.

Roe, D. A. (1981): The Lower and Middle Palaeolithic periods in Britain. - London, Boston (Routledge \& Kegan Paul).

RoTH, V. L. (1984): How elephants grow: heterochrony and calibration of developmental stages in some living and fossil species. - Journal of Vertebrate Paleontology $\mathbf{4}$ : 126-145.

Santonja, M. \& Villa, P. (1990): The lower Palaeolithic of Spain and Portugal. - Journal of World Prehistory 4 : 45-93; New York, London.

SCHIRMER, W. (1990): Kärlich - Forschungsstand 1990. - In: Schirmer, W. [Hrsg.]: Rheingeschichte zwischen Mosel und Maas. - S. 60-67; DEUQUA Führer 1; Hannover.

Segre, A. G.; Biddittu, I. \& Guadagnoli, F. (1987): Nuovi dati sul giacimento del Paleolitico Inferiore di AnagniFontana Ranuccio. - Archeologia Laziale 8: 239-243; Roma.

Shipman, P. (1981): Life history of a fossil. - Cambridge, Mass. (Havard University Press).

SPICER, R. A. (1989): The formation and interpretation of plant fossil assemblages. - In: CAllow, J. A. [Hrsg.]: Advances in Botanical Research. - S. 95-191; London, San Diego (Academic Press).

Steppan, K. H. (1993): Osteologische und taphonomische Untersuchungen an Tierknochenfunden aus der mesolithischen Freilandfundstelle Rottenburg-Siebenlinden I, Lkr. Tübingen. - Zeitschrift für Archäologie 27: 9-16.

STINER, M. C. (1994): Honor among thieves. - Princeton (Princeton University Press).

STOCKTON, D. E. (1973): Shaw's Creek shelter: human displacement of artefacts and its significance. - Mankind 9: 112-117; Sydney.

Street, M.; BaAles, M. \& Weninger, B. (1994): Absolute Chronologie des späten Paläolithikums und Frühme- 
solithikums im nördlichen Rheinland. Archäologisches Korrespondenzblatt 24, 1-28; Mainz.

Turner, E. (1989): Middle and Late Pleistocene macrofaunas of the Neuwied Basin region (Rhineland-Palatinate) of West Germany. - Unveröffentlichte Dissertation, 360 S.; Birmingham.

Villa, P. (1982): Conjoinable pieces and site formation processes. - American Antiquity 47: 276-290; Menasha.

- (1990): Torralba and Aridos: elephant exploitation in Middle Peistocene Spain. - Journal of Human Evolution 19: 299-309; London.

- \& Courtin, J. (1983): The interpretation of stratified sites: a view from underground. - Journal of Archaeological Science 10: 267-281; London.
VollBrecht, J. (1992): Das Altpaläolithikum aus den unteren Schichten in Kärlich. Unveröffentlichte Magisterarbeit, 123 S.; Köln.

WooD, W. R. \& Johnson, D. L. (1978): A survey of disturbance processes in archaeological site formation. - In: SCHIFFER, M. B. [Hrsg.]: Advances in archaeological method and theory. Vol. 1. - S. 315-381; New York, San Francisco (Academic Press).

ZAGWIJN, W. H. (1985): An outline of the Quaternary stratigraphy of the Netherlands. Geologie en Mijnbouw $\mathbf{6 4}$ : 17-24; s'-Gravenhage.

Manuskript eingegangen am 25.08.1995 